\title{
Isoniazid Preventive Therapy in Contacts of Multidrug-resistant Tuberculosis
}

1. Chuan-Chin Huang, Sc.D., Brigham and Women's Hospital, Division of Global Health Equity, 75 Francis Street, Boston, Massachusetts 02115, United States; Department of Global Health and Social Medicine, Harvard Medical School, 641 Huntington Avenue, Boston, Massachusetts 02115, United States.

2. Mercedes C. Becerra, Sc.D., Department of Global Health and Social Medicine, Harvard Medical School, 641 Huntington Avenue, Boston, Massachusetts 02115, United States.

3. Roger Calderon, M.S., Partners in Health - Socios En Salud Sucursal, Av. Chimpu Ocllo \# 998 Urb. Residencial Lucyana, Carabayllo, Lima, Peru.

4. Carmen Contreras, M.P.H., Partners in Health - Socios En Salud Sucursal, Av. Chimpu Ocllo \# 998 Urb. Residencial Lucyana, Carabayllo, Lima, Peru.

5. Jerome Galea, Ph.D., School of Social Work, University of South Florida, 13301 Bruce B Downs Blvd, MHC 1416 A, Tampa, Florida 33612, USA

6. Louis Grandjean, Ph.D., Wellcome Centre for Clinical Tropical Medicine, Imperial College London, London WC1H 9JJ, United Kingdom; Universidad Peruana Cayetano Heredia, Av. Honorio Delgado 430, Urb Ingeniería, Lima, Peru; TB Centre, London School of Hygiene \& Tropical Medicine, Keppel Street, London WC1E 7HT, United Kingdom.

7. Leonid Lecca, M.D., Partners in Health - Socios En Salud Sucursal, Av. Chimpu Ocllo \# 998 Urb. Residencial Lucyana, Carabayllo, Lima, Peru. 
8. Rosa Yataco, Partners in Health - Socios En Salud Sucursal, Av. Chimpu Ocllo \# 998 Urb. Residencial Lucyana, Carabayllo, Lima, Peru.

9. Zibiao Zhang, M.S., Brigham and Women's Hospital, Division of Global Health Equity, 75 Francis Street, Boston, Massachusetts 02115, United States.

10. Megan Murray, M.D., Sc.D., Harvard Medical School, Department of Global Health and Social Medicine, Boston, Massachusetts, United States and Brigham and Women's Hospital, Division of Global Health Equity, Boston, Massachusetts, United States

\section{Correspondence to:}

Dr Megan Murray, M.D., Sc.D.

Department of Global Health and Social Medicine, Harvard Medical School

641 Huntington Avenue

4th Floor, Room 4A07

Boston, MA 02115

Email: megan_murray@,hms.harvard.edu

Phone: 617.432 .2781

Fax: 617.566.7805

Author Contributions: MBM and MCB led the study design. LL oversaw data collection and management with JTG, RC, ZZ, CC, and RY. RC managed laboratory efforts. LG conducted the second independent cohort study. MBM supervised data analysis and interpretation in conjunction with $\mathrm{C}-\mathrm{CH}$ and $\mathrm{MFF}$. C-CH and MBM wrote the first draft of the manuscript, and all authors contributed to manuscript revision. 
Funding source: This work was supported by the National Institutes of Health and the National Institute of Allergy and Infectious Diseases: U01AI057786, U19AI076217, CETR [U19AI109755] and TBRU [U19AI111224].

Running title: Impact of isoniazid on MDR-LTBI

\section{Descriptor number: 11.6}

Word count: 3,426

Impact of this research on clinical medicine: We found that isoniazid preventive therapy protected contacts of multidrug-resistant tuberculosis patients from developing tuberculosis disease. Isoniazid preventive therapy effectiveness was greater among contacts who received more than three months of preventive therapy and who were less than five years old. We observed similar effects in a secondary independent cohort study. Our findings suggest that isoniazid may have a role in the management of multidrug-resistant latent tuberculosis infection.

This article has an online data supplement, which is accessible from this issue's table of content online at www.atsjournals.org.

Some of the results of these studies have been previously reported in the form of a preprint (bioRxiv, 23 January 2019 https://doi.org/10.1101/479865v4) 


\begin{abstract}
Rationale: The World Health Organization recommends the use of isoniazid alone or in combination with rifapentine to treat latent tuberculosis infection. The recent rise of drugresistant tuberculosis has complicated the choice of latent tuberculosis infection treatment regimen.
\end{abstract}

Objectives: To evaluate the effects of isoniazid preventive therapy on contacts of multidrugresistant tuberculosis patients

Methods: In a prospective cohort study conducted between September 2009 and August 2012, we identified 4,500 index tuberculosis patients and 14,044 tuberculosis-exposed household contacts whom we followed for one year for the occurrence of incident tuberculosis disease. Although Peruvian national guidelines specify that isoniazid preventive therapy should be provided to contacts aged 19 and under, only half this group received isoniazid preventive therapy.

Measurements and Main Results: Among 4,216 contacts under 19 years of age, 2,106 (50\%) initiated isoniazid preventive therapy at enrollment. The protective effect of isoniazid was more extreme in contacts exposed to drug-sensitive (adjusted hazard ratio, 0.30 [95\% confidence interval, 0.18-0.48]) and to multidrug-resistant tuberculosis $(0.19$ [0.05-0.66]) compared to those exposed to mono-isoniazid-resistant $(0.80$ [0.23-2.80]). In the second independent study, tuberculosis occurred in none of the 76 household contacts who received isoniazid preventive therapy compared to $3 \%(8 / 273)$ of those who did not.

Conclusion: Household contacts who received isoniazid preventive therapy had a lower incidence of tuberculosis disease even when they had been exposed to an index patient with 
multidrug-resistant tuberculosis. Isoniazid may have a role in the management of latent multidrug-resistant tuberculosis infection.

Key words: tuberculosis; multidrug-resistant tuberculosis; isoniazid; isoniazid preventive therapy 


\section{Introduction}

The World Health Organization (WHO) estimates that there were 10 million new cases of tuberculosis in 2017 and that one quarter to one third of the world's population has latent tuberculosis infection (LTBI) $(1,2)$. Although treatment of LTBI has been shown to prevent tuberculosis disease progression, only a minority of those at risk receive preventive therapy (2). WHO's recently revised guidelines now recommend testing and treatment of LTBI for an expanded group at risk of tuberculosis disease including household contacts of pulmonary tuberculosis patients (2). Recommended regimens for LTBI include six to nine months of isoniazid, a three-month regimen of rifapentine plus isoniazid, three to four months of isoniazid and rifampicin, and three to four months of rifampicin alone (2).

The recent rise of drug resistant tuberculosis has complicated the choice of an LTBI regimen. Although several small studies have suggested that regimens tailored to specific drugsusceptibility profiles can be effective, most either lacked control arms or compared these regimens to no treatment rather than an alternative regimen (3). WHO concludes that the current lack of evidence on optimal regimens prevents the formulation of definitive recommendations for contacts exposed to drug resistant tuberculosis (2).

In countries that implement preventive therapy for those at high risk, household contacts of multidrug-resistant (MDR) tuberculosis patients often receive standard LTBI regimens prior to time that the index patient's drug susceptibility tests are available to the treating clinician. In areas where rapid diagnostic tests for MDR are not yet available, contacts may receive isoniazid for months prior to the eventual diagnosis of $\operatorname{MDR}(4,5)$. Here, we examined the risk of disease progression of individuals who received isoniazid preventive therapy as part of routine 
tuberculosis management stratified by the drug resistance profile of the index patient. Some of the results of this study have been previously reported in the form of an abstract (6).

\section{Methods}

\section{Setting and recruitment}

This study was conducted in Lima, Peru in a catchment area of approximately three million residents. We identified and enrolled all patients newly diagnosed with pulmonary tuberculosis and over 15 years of age who presented at 106 district health centers. We confirmed the microbiological status of their pulmonary tuberculosis disease with either a positive sputum smear or mycobacterial culture. We then recruited their household contacts into a prospective cohort study.

\section{Baseline and follow-up assessments of index patients and household contacts}

We collected data from index patients on the duration of symptoms before diagnosis, presence of cavitary disease on chest radiography, sputum smear status, and mycobacterial culture results. We performed drug susceptibility testing on isolates from culture positive patients. We collected the following data from both index patients and household contacts at the time of enrollment: age, height, weight, gender, occupation, history of tuberculosis disease, alcohol use, education, type of housing, frequency of public transportation use, tobacco history, symptoms of tuberculosis, BCG vaccination, recreational drug use, and comorbidities including HIV and diabetes mellitus. All enrolled household contacts were assessed for the presence of tuberculosis disease and received a tuberculin skin test to determine infection status at baseline, 6-month and 12-month follow-up. 
Isoniazid preventive therapy for household contacts

The 2006 Peruvian National tuberculosis Program guidelines recommended that household contacts aged 19 or younger and adults with specified comorbidities should receive a course of isoniazid preventive therapy (7). Health care providers sometimes chose to discontinue isoniazid preventive therapy in household contacts if the index patient was subsequently found to be infected with a strain that was resistant to isoniazid but many such household contacts received a full course of isoniazid preventive therapy. We used medical records from participating hospitals and health clinics to determine whether household contacts received isoniazid preventive therapy and the duration of their regimen.

\section{Incident tuberculosis disease}

We identified incident tuberculosis among household contacts during scheduled household visits at 2, 6 and 12 months after enrollment and through a review of tuberculosis registries at the participating health clinics to ensure we obtained all the incident tuberculosis cases among HCCs during the one year follow-up. We considered household contacts to have co-prevalent tuberculosis if they were diagnosed within two weeks of the diagnosis of the index patient and to have secondary tuberculosis otherwise. We defined tuberculosis disease among contacts younger than 18 years of age according to the consensus guidelines for classifying tuberculosis disease in children (8). Paired-end whole genome sequencing using the Illumina HiSeq 4000 platform was performed on isolates from all culture positive incident tuberculosis cases and their index cases if the index cases were also culture positive. 
A detailed description of this study setting, design, study design, outcome definition, and data collection process has been previously reported in the supplementary document of Becerra et al., 2019 (9). We also provided a brief version of data collection and variable assessments in the Online Data Supplement of this manuscript.

\section{Analyses}

We restricted the analysis to household contacts under 19-year-olds because older contacts received isoniazid preventive therapy only if they had comorbidities that substantially increased their risk of tuberculosis disease. We used a Cox frailty proportional hazards model to evaluate risk factors for incident tuberculosis disease, accounting for clustering within households (10). We first performed a univariate analysis to examine the effect of isoniazid preventive therapy on tuberculosis incidence, followed by a multivariate model adjusting for potential confounders: age, sex, alcohol use, tobacco use, recreational drug use, and employment status of the index patient; age, sex, alcohol use, tobacco use, employment status, use of public transportation, BCG vaccination history, and tuberculosis history of the HHC; household socioeconomic status (SES), incarceration history, residential district, and household education level. We used a backward stepwise regression criteria with alpha level $=0.2$ to the multivariate models. To evaluate whether the effect of isoniazid preventive therapy varied by the index patient's resistance profile, we included resistance profile and an interaction term for resistance and isoniazid preventive therapy use. Because the spectrum of isoniazid-resistance causing mutations that lead to isoniazid mono-resistance may differ from those that lead to MDRtuberculosis, we classified strains as sensitive, mono-isoniazid-resistant, or MDR-tuberculosis (resistant to both isoniazid and rifampin). Previous studies have shown that the effectiveness of 
isoniazid preventive therapy treatment is reduced if the treatment duration is less than three months (11). We therefore repeated these analyses stratifying on duration of treatment. We conducted two sensitivity analyses. We first restricted the analyses to household contacts undersix-years old as we considered this age group most likely to have acquired tuberculosis from the index patient rather than from a community exposure. Secondly, we restricted the analyses to household contacts who were infected at baseline. We also repeated these analyses in the subset of household contacts exposed to index patients for whom quantitative isoniazid-resistance (mean inhibitory concentrations) was available. All the analyses were performed using R program (12). The IRB number of the study cohort is 19332. IRB approved the use of a small proportion of data without additional patient consent.

\section{Analyses of publicly available data}

We analyzed publicly available data from a second independent prospective cohort study conducted in Lima, Peru between 2010 and 2013, posted by Grandjean et al. (13). This study measured incident tuberculosis over two years of follow up in 1,055 household contacts of 213 MDR-tuberculosis index patients and 2,362 household contacts of 487 drug-susceptible index patients. Drug susceptibility testing for isoniazid and rifampin was performed on isolates from all index patients and secondary cases whose isolates were available using microscopic-observationdrug-susceptibility assays in regional laboratories. Results were confirmed by proportions methods in the Peru national reference laboratory (14). Isoniazid preventive therapy was reportedly discontinued in this group after MDR-tuberculosis index cases were confirmed but data on the duration of isoniazid preventive therapy were not available. Among the incident cases with drug susceptibility tests results available, $86 \%$ of those exposed to MDR-tuberculosis 
also had MDR-tuberculosis, and $98 \%$ of those exposed to drug-sensitive tuberculosis also had drug-sensitive tuberculosis. We analyzed the data using the approach described above.

\section{Results}

We identified 4,500 tuberculosis patients and 14,839 household contacts. We received consent forms from 14,044 household contacts $(94.6 \%)$. The retention rates for enrolled household contacts at 12 months of follow-up was 92.0\%, respectively. Among the enrolled household contacts, 12,767 had been exposed to index patients with microbiologically confirmed tuberculosis. Of these, 4,216 were aged 19 or under (supplementary Figure S1); 2,096 (50\%) of these received a course of isoniazid preventive therapy. Table 1 showed that the distribution of baseline characteristics did not vary by the index case drug-resistant profiles. Table 2 and Table S1-S3 showed that the baseline characteristics stratified by isoniazid preventive therapy status. The mean duration of isoniazid preventive therapy was 115 days among household contacts of MDR-tuberculosis cases compared to 142 days for household contacts of patients resistant to isoniazid alone and 148 days for household contacts exposed to MDR-tuberculosis (Figure S2). At 12-months, 146 under-19-year-olds were diagnosed with tuberculosis disease. Based on the distribution of the number of single nucleotide polymorphisms (SNPs) identified by whole genome sequencing that differed between the household pairs (Figure S3), we chose a cut-off of 10 single nucleotide polymorphisms or less to identify strains that we assumed had been transmitted from the index patient to the secondary case. Among the 52 secondary cases who were culture positive and for whom whole-genome sequencing were therefore available, the isolates of $38(73 \%)$ matched those of the index patients. 
Compared to those who did not receive treatment, household contacts who received isoniazid preventive therapy were one third as likely to be diagnosed with tuberculosis disease in both the univariate and multivariate models (Figure 1) (hazard ratio $[\mathrm{HR}]=0.33,95 \%$ confidence interval $[C I]=0.22-0.48$ and adjusted $H R=0.31,95 \% \mathrm{CI}=0.20-0.47)($ Table S4). Figure 2 (Table S5) shows that isoniazid was more effective in household contacts exposed to drug-sensitive or MDR tuberculosis than in those exposed to strains resistant to isoniazid alone (isoniazid preventive therapy vs. No-isoniazid preventive therapy adjusted $\mathrm{HR}=0.30,95 \% \mathrm{CI}=0.18-0.48$ in isoniazidsensitive subgroup; [0.19; 0.05-0.66] in MDR subgroup; $(0.80 ; 0.23-2.80)$ in mono-isoniazidresistant subgroup). Isoniazid efficacy increased with the duration of therapy across all three resistance categories (Figure 3 and Table S5). None of the participants five years old or less who received more than three months treatment developed tuberculosis disease during follow-up (Table 3A-3C). When we restricted the analyses to a sub-cohort who were infected at baseline, the protective effect of IPT on the contacts of MDR patients remained strong (adjusted HR=0.14 [0.02-1.07]) (Table S6). Among 1,276 household contacts for whom index patient minimal inhibitory concentrations (MICs) were available, the effectiveness of isoniazid preventive therapy did not vary by isoniazid MIC; among 92 household contacts who received isoniazid preventive therapy after being exposed to an index patient with an $\mathrm{MIC}>5 \mu \mathrm{g} / \mathrm{ml}$, none developed (0/92) active tuberculosis, while 4\% (14/368) of those who did not receive isoniazid preventive therapy developed disease.

\section{Second independent dataset}

The previously reported cohort described above included 1,121 household contacts $\leq 19$ years age whose isoniazid preventive therapy status was known. Isoniazid preventive therapy use was 
associated with reduced rates of incident tuberculosis in both univariate and analyses that adjusted for age, $\mathrm{SES}$, and tuberculosis history $(\mathrm{HR}=0.1 ; 95 \% \mathrm{CI}=0.03-0.30$ and adjusted $\mathrm{HR}=0.11 ; 95 \% \mathrm{CI}=0.02-0.49)$. Isoniazid preventive therapy not only protected household contacts of drug-sensitive index cases (adjusted $\mathrm{HR}=0.1395 \% \mathrm{CI}=0.03-0.57$ ), but none of 76 household contacts of MDR-tuberculosis index cases who received isoniazid preventive therapy developed tuberculosis compared to $8 / 273(3 \%)$ without isoniazid preventive therapy.

\section{Discussion}

Here, we found that isoniazid preventive therapy use is associated with reduced rates of tuberculosis disease among household contacts of tuberculosis patients even when the index patients were infected with isoniazid-resistant and MDR strains of tuberculosis. Notably, isoniazid effectiveness was higher among household contacts of MDR-tuberculosis than among people exposed to strains resistant to isoniazid alone. Isoniazid effectiveness increased with the duration of therapy regardless of the resistance profile of the index patient. Among those under 5 years of age, the group most likely to have been infected by the index patient, none of the children who received at least three months of isoniazid preventive therapy developed tuberculosis disease. We found that the effectiveness of isoniazid preventive therapy was not associated with the isoniazid MIC of the index patient's tuberculosis strain; no household contact who was exposed to an index patient with a $>5 \mu \mathrm{g} / \mathrm{ml}$ isoniazid MIC developed disease.

Few data exist on the effectiveness of isoniazid in preventing tuberculosis progression among people exposed to drug-resistant tuberculosis (table S7). In a study from Brazil, investigators reported that among 190 MDR-exposed contacts, disease occurred in two of 45 (4\%) who received isoniazid preventive therapy and in 13 of $145(9 \%)$ who did not (15). A similar study 
from Israel reported no cases over 6 years of follow up among 71 MDR-tuberculosis-exposed contacts who received isoniazid preventive therapy (16). A study in South African children found that those who received no preventive therapy were four times more likely to develop tuberculosis disease than those who received an individualized regimen that included high dose isoniazid but could draw no conclusions about the efficacy of isoniazid alone because regimens were tailored to the drug susceptibility profile of the index strain (17). Another study in South African children found no cases over one year of follow up among 21 MDR-exposed children who received ofloxacin, ethambutol and high-dose isoniazid (18). An Australia study compared tailored preventive regimens to either isoniazid preventive therapy or no treatment among MDR exposed contacts (19). Two contacts in the isoniazid preventive therapy/no-treatment arm developed tuberculosis disease within 54 months, but the study did not specify whether the two incident patients received isoniazid preventive therapy or not. Finally, a study conducted in Beijing followed students during an MDR TB outbreak and found two cases among five IPT recipients and 4 cases among 16 IPT non-recipients over 6 months of follow-up (20). Other studies which reported on regimens that included isoniazid among contacts of MDR/DRtuberculosis patients lacked control arms (21-22).

We considered possible explanations for the observed effectiveness of isoniazid preventive therapy among contacts of isoniazid-resistant tuberculosis patients. It is possible that household contacts were not infected by their isoniazid-resistant index patient but instead acquired a drugsensitive infection from an unknown contact in the community. The finding that the majority of the household contacts who developed tuberculosis in both studies either harbored strains that were almost genetically identical or shared the same drug susceptibility tests profiles with their index case argues against this explanation as does our finding that the protective effect of 
isoniazid preventive therapy was more marked in under-5 year olds, whom we considered much less likely than older contacts to have been infected by someone other than the index case. We also considered the possibility that isoniazid preventive therapy use might be confounded by socioeconomic status in these observational studies. Although we have tried to adjust for possible confounding, we still cannot rule out the possibility of residual confounding. We note, however, that since the distributions of these variables were very similar between HHCs exposed to DS-TB and MDR-TB, any residual confounding would be expected to have a similar impact in the DS and MDR-exposed HHCs. Therefore, our findings should be robust even if there were some residual confounding by socioeconomic status. Furthermore, the reduced efficacy of isoniazid preventive therapy among people who received less than one month of treatment is within the range reported in a seminal randomized trial, again suggesting that residual confounding is unlikely to explain our findings (13).

Finally, we considered the possibility that isoniazid might be effective against LTBI even when the relevant strains are found to be resistant to isoniazid in media-based growth assays. This raises the possibility that the mechanism by which isoniazid reduces tuberculosis risk among those with LTBI may differ from its mechanism in tuberculosis disease. Isoniazid is known to be a pro-drug which is converted to its active metabolite, an isoniazid-NAD adduct, by a Mycobacterium tuberculosis (MTB) catalase peroxidase encoded by the KatG gene (23). The isoniazid-NAD adduct then binds to InhA (an enoyl-acyl carrier protein reductase) and inhibits the synthesis of essential mycolic acids in MTB cell walls. Mutations in KatG that reduce the activity of the catalase-peroxidase block the conversion of isoniazid to its active form and result in isoniazid resistance. Several studies have raised the possibility that the conversion of isoniazid to its active form may occur independently of the mycobacterial catalyst peroxidase. One group 
found that the presence of copper increased the isoniazid sensitivity of an otherwise isoniazidresistant strain, suggesting the interaction of isoniazid and copper ions may facilitate the conversion of isoniazid to its active form $(23,24)$. Two recent studies showed that eosinophil- or neutrophil-derived myeloperoxidase was able to produce the isoniazid-NAD adduct $(25,26)$. Another research identified metabolites of oxidized isoniazid-NAD adducts in the urine of people who were not infected with MTB, thereby raising the possibility that isoniazid can be activated by host enzymes (27). Other studies have suggested that isoniazid may employ nonspecific antibacterial mechanisms against MTB in addition to its impact on mycolic acid synthesis. For example, isoniazid is a strong ligand for iron, copper and zinc and might be involved in metal ion uptake by MTB, which could disrupt metal homeostasis and inhibit MTB growth (27-31). Other investigators have posited a role for a host-immuno-modulation of isoniazid (32-34). In one study, investigators examined the impact of INH on cultured human promyelocytic leukemia (HL-60) cells as a model for human phagocytes and found that it protected them from MTB-induced oxidative stress mediated necrosis (33). In another study, INH was found to induce the differentiation of pro-inflammatory monocytes in HL-60 cells. The investigators speculate that INH works by bolstering the pro-inflammatory response in monocytes in granulomas, rather than through a direct bacteriocidal effect (34). None of these hypotheses directly address the question of why isoniazid fails to cure active TB disease in patient with isoniazid-resistant strains. It is possible that these mechanisms clear MTB in the early stage of infection when the MTB is restricted to the granuloma and bacterial load is low, but are less effective when the MTB is released outside the granuloma and the bacterial load is much higher. 
We also found that the protective effect of isoniazid differs in contacts exposed to MDRtuberculosis strains compared to mono-isoniazid-resistant strains. Given the small number of patients with isoniazid resistance alone, it is possible that this difference is the result of statistical imprecision. However, previous studies have shown that the distribution of isoniazid-causing mutation differs between MDR and mono-isoniazid-resistant strains, with mono-isoniazidresistant strains being more likely than MDR strains to harbor InhA promoter mutations and less likely to have KatG mutations (35). Since InhA is the downstream target of the isoniazid-NAD adduct, it is possible that mono-isoniazid-resistant strains remain resistant to isoniazid regardless of whether isoniazid conversion takes through an MTB-dependent or independent pathway.

Our study has some limitations. Like any observational study, it is possible that unmeasured factors associated with both tuberculosis susceptibility and isoniazid preventive therapy use have created the appearance of an association that is not causal. The contacts of MDR-tuberculosis cases also received isoniazid for a shorter period of time than contacts of pan-sensitive or monoisoniazid-resistant cases, presumably because clinicians halted isoniazid preventive therapy once the index patients' MDR-tuberculosis status were confirmed. Given the dose effect we observed, we would expect to see an even more extreme effect of isoniazid preventive therapy had contacts of MDR-tuberculosis cases received the same duration of isoniazid preventive therapy as those exposed to drug-sensitive strains. Furthermore, we were unable to assess the effect of isoniazid preventive therapy on adult contacts of MDR-tuberculosis cases given that isoniazid preventive therapy is not indicated for adult contacts without co-morbidities in Peru. Finally, almost all household contacts in our cohort were HIV-negative, so we were not able to evaluate the synergistic effect between isoniazid preventive therapy and highly active antiretroviral therapy in HIV-positive household contacts exposed to MDR-tuberculosis. 
In conclusion, we found that isoniazid preventive therapy protected against tuberculosis among contacts of MDR tuberculosis patients. Given the safety profile of isoniazid and its wide use across the globe, isoniazid may have a role in the management of MDR-LTBI.

\section{Declaration of Interests}

Authors declare no competing interests.

\section{Acknowledgments}

We thank the patients and their families who gave their time and energy to contribute to this study, the National Tuberculosis Program at the Peruvian Ministry of Health, and the healthcare personnel at the 106 participating health centers in Lima, Peru. This work was supported by the National Institutes of Health and the National Institute of Allergy and Infectious Diseases U01AI057786, U19AI076217, CETR [U19AI109755] and TBRU [U19AI111224]. 


\section{References}

1. http://www.who.int/tb/publications/factsheet_global.pdf?ua=1 (accessed April 1, 2019).

2. World Health Organization Latent tuberculosis infection, updated and consolidated guidelines for programmatic management. Geneva, Switzerland, 2018. Available from: http://www.who.int/tb/publications/2018/latent-tuberculosis-infection/en/ (accessed December 1, 2018).

3. Fox GJ, Dobler CC, Marais BJ, Denholm JT. Preventive therapy for latent tuberculosis infection-the promise and the challenges. Int J Infect Dis 2017; 56: 68-76.

4. Jacobson KR, Theron D, Kendall EA, Franke MF, Barnard M, van Helden PD, et al. Implementation of genotype MTBDRplus reduces time to multidrug-resistant tuberculosis therapy initiation in South Africa. Clin Infect Dis 2013; 56: 503-8.

5. Boehme CC, Nicol MP, Nabeta P, Michael JS, Gotuzzo E, Tahirli R, et al. Feasibility, diagnostic accuracy, and effectiveness of decentralised use of the Xpert MTB/RIF test for diagnosis of tuberculosis and multidrug resistance: a multicentre implementation study. Lancet 2011; 377: 1495-1505.

6. Huang CC, Becerra MC, Calderon R, Contreras C, Jerome G, Grandjean L, et al. Isoniazid preventive therapy protects against tuberculosis among household contacts of isoniazidresistant patients [abstract]. Vancouver, BC, Canada: 23rd Annual Conference of The Union -North America Region; 2019. 
7. Ministerio de Salud. Norma técnica de salud para el control de la tuberculosis. Lima, Peru, 2006. Available from: ftp://ftp2.minsa.gob.pe/descargas/dgsp/ESNtuberculosis/normaspublicaciones/NTSTBC.pdf (accessed October 10, 2018).

8. Graham SM, Ahmed T, Amanullah F, Browning R, Cardenas V, Casenghi M, et al. Evaluation of tuberculosis diagnostics in children: 1. Proposed clinical case definitions for classification of intrathoracic tuberculosis disease. Consensus from an expert panel. J Infect Dis 2012; 205(Suppl 2): S199-208.

9. Becerra CM, Huang CC, Lecca L, Bayona J, Contreras C, et al. Transmissibility and potential for disease progression of drug resistant Mycobacterium tuberculosis: prospective cohort study. BMJ, 2019; 24(367): 15894.

10. O'Quigley J, Stare J. Proportional hazards models with frailties and random effects. Stat Med 2002; 21(21): 3219-33.

11. International Union Against Tuberculosis Committee on Prophylaxis. Efficacy of various durations of isoniazid preventive therapy for tuberculosis: five years of follow-up in the UAT trial. Bull World Health Organ 1982; 60: 555-64.

12. R Core Team (2017). R: A language and environment for statistical computing. $\mathrm{R}$ Foundation for Statistical Computing, Vienna, Austria. URL https:/www.R-project.org/.

13. Grandjean L, Gilman RH, Martin L, Soto E, Castro B, Lopez S, et al. Transmission of Multidrug-Resistant and Drug-Susceptible Tuberculosis within Households: A Prospective Cohort Study. PLoS Med 2015; 12(6): e1001843. 
14. Caviedes L, Lee TS, Gilman RH, Sheen P, Spellman E, Lee EH, et al. Rapid, efficient detection and drug susceptibility testing of Mycobacterium tuberculosis in sputum by microscopic observation of broth cultures. The Tuberculosis Working Group in Peru. J Clin Microbiol 2000; 38: 1203-8.

15. Kritski AL, Marques MJ, Rabahi MF, Vieira MA, Werneck-Barroso E, Carvalho CE, et al. Transmission of tuberculosis to close contacts of patients with multidrug-resistant tuberculosis. Am J Respir Crit Care Med 1996; 153(1): 331-5.

16. Attamna A, Chemtob D, Attamna S, Fraser A, Rorman E, Paul M, et al. Risk of tuberculosis in close contacts of patients with multidrug resistant tuberculosis: a nationwide cohort. Thorax 2009; 64: 271.

17. Schaaf HS, Gie RP, Kennedy M, Beyers N, Hesseling PB, Donald PR. Evaluation of young children in contact with adult multidrug-resistant pulmonary tuberculosis: a 30-month follow-up. Pediatrics 2002; 109: 765-71.

18. Garcia-Prats AJ, Zimri K, Mramba Z, Schaaf HS, Hesseling AC. Children exposed to multidrug-resistant tuberculosis at a home-based day care centre: a contact investigation. Int J Tuberc Lung Dis 2014; 18: 1292-8.

19. Denholm JT, Leslie DE, Jenkin GA, Darby J, Johnson PD, Graham SM, et al. Long-term follow-up of contacts exposed to multidrug-resistant tuberculosis in Victoria, Australia, 1995 -2010. Int J Tuberc Lung Dis 2012; 16: 1320-5. 
20. Wu X, Pang Y, Song Y, Dong W, Zhang T, Wen S, et al. Implications of a school outbreak of multidrug-resistant tuberculosis in Northern China. Epidemiol Infect 2018; 145(5):584-8.

21. Seddon JA, Hesseling AC, Finlayson H, Fielding K, Cox H, Hughes J, et al. Preventive therapy for child contacts of multidrug-resistant tuberculosis: a prospective cohort study. Clin Infect Dis 2013; 57: 1676-84.

22. Tochon M, Bosdure E, Salles M, Beloncle C, Chadelat K, Dagorne M, et al. Management of young children in contact with an adult with drug-resistant tuberculosis, France, 2004-2008. Int J Tuberc Lung Dis 2011; 15: 326-30.

23. Bernardes-Génisson V, Deraeve C, Chollet A, Bernadou J, Pratviel G. isoniazid: an update on the multiple mechanisms for a singular action. Curr Med Chem 2013; 20(35): 4370-85.

24. Youatt, J. The influence of copper on the uptake of hydrazides. Aust J Exp Biol 1962; 40: $201-6$.

25. Khan SR, Morgan AG, Michail K, Srivastava N, Whittal RM, Aljuhani N, et al. Metabolism of isoniazid by neutrophil myeloperoxidase leads to INH-NAD+ adduct formation: A comparison of the reactivity of isoniazid with its known human metabolites. Biochem Pharmacol 2016; 106, 46-55.

26. Babu D, Morgan, AG, Reiz B, Whittal RM, Almas S, Lacy P, et al. Eosinophil peroxidase oxidizes isoniazid to form the active metabolite against M. tuberculosis, isoniazid-NAD+. Chem Biol Interact 2019; 305, 48-53. 
27. Mahapatra S, Woolhiser LK, Lenaerts AJ, Johnson JL, Eisenach KD, Joloba ML, et al. A novel metabolite of antituberculosis therapy demonstrates host activation of isoniazid and formation of the isoniazid-NAD+ adduct. Antimicrob Agents Chemother 2012; 56(1): 28-35.

28. Rodriguez GM. Control of iron metabolism in Mycobacterium tuberculosis. Trends Microbiol 2006; 14(7): 320-7.

29. Ratledge, C. Iron, mycobacteria and tuberculosis. Tuberculosis, 2004; 84(1-2): 110-30.

30. Botella H, Peyron P, Levillain F, Poincloux R, Poquet Y, Brandli I, et al. Mycobacterial p(1)type ATPases mediate resistance to zinc poisoning in human macrophages. Cell Host Microbe 2011; 10(3): 248-59.

31. Zumla A, Atun R, Maeurer M, Mwaba P, Ma Z, O’Grady J, et al. Viewpoint: Scientific dogmas, paradoxes and mysteries of latent Mycobacterium tuberculosis infection. Trop Med Int Health 2011; 16(1): 79-83.

32. Khan SR, Manialawy Y, Siraki AG. Isoniazid and host immune system interactions: A proposal for a novel comprehensive mode of action. Br J Pharmacol. 2019 Sep.

33. Khan SR, Aljuhani N, Morgan AGM, Baghdasarian A, Fahlman RP, Siraki AG. Cytoprotective effect of isoniazid against $\mathrm{H} 2 \mathrm{O} 2$ derived injury in HL-60 cells. Chem Biol Interact $2016244 ; 37-48$.

34. Babu D, Khan SR, Srivastava N, Kyoung Suh LY, Morgan AG, Aljuhani N, et al. Isoniazid induces a monocytic-like phenotype in HL-60 cells. Arch Biochem Biophys 2019; 664 15-23. 
35. Hazbón MH, Brimacombe M, Bobadilla del Valle M, Cavatore M, Guerrero MI, VarmaBasil M, et al. Population genetics study of isoniazid resistance mutations and evolution of multidrug-resistant mycobacterium tuberculosis. Antimicrob Agents Chemother 2006; 50(8): 2640-9. 


\section{Figure Legends}

Figure 1. Effect of isoniazid prevention therapy on disease incidence of household contacts $\leq 19$ years of age. Multivariate model adjusted for index case age, recreational drug use, household contact age, gender, BCG-vaccination scar, nutritional status, being a student or not, tuberculosis history, household socioeconomic status, and household residential district.

Figure 2. The effect of isoniazid prevention therapy on tuberculosis incidence in $\leq 19$ year olds, by isoniazid resistance status of index patient, adjusted for index case age, recreational drug use, household contact age, gender, BCG-vaccination scar, nutritional status, being a student or not, tuberculosis history, household socioeconomic status, and household residential district.

Figure 3. The effect of $\geq 3$ months (A) or $<3$ months (B) isoniazid prevention therapy on tuberculosis incidence in $\leq \mathbf{1 9}$ year olds, by isoniazid resistance status of index patient, adjusted for index case age, recreational drug use, household contact age, gender, BCG-vaccination scar, nutritional status, being a student or not, tuberculosis history, household socioeconomic status, and household residential district. 
Table 1. Baseline characteristics of household contacts $\leq 19$ years old, stratified by DST profile of index case.

\begin{tabular}{|c|c|c|c|c|c|c|c|}
\hline \multirow[t]{2}{*}{ Characteristic } & \multicolumn{2}{|c|}{ DS index cases } & \multicolumn{2}{|c|}{ INH-R index cases } & \multicolumn{2}{|c|}{$\begin{array}{c}\text { MDR index } \\
\text { cases }\end{array}$} & \multirow[t]{2}{*}{ p-value } \\
\hline & $\mathrm{N}$ & $\%$ & $\mathrm{~N}$ & $\%$ & $\mathrm{~N}$ & $\%$ & \\
\hline $\begin{array}{l}\text { Age in years } \\
(\mathrm{N}=4,216)\end{array}$ & & & & & & & 0.55 \\
\hline 0 to 5 & 1,143 & $36 \%$ & 134 & $35 \%$ & 242 & $36 \%$ & \\
\hline 6 to 10 & 741 & $23 \%$ & 80 & $21 \%$ & 150 & $23 \%$ & \\
\hline 11 to 15 & 703 & $22 \%$ & 85 & $22 \%$ & 152 & $23 \%$ & \\
\hline 16 to 19 & 577 & $18 \%$ & 87 & $23 \%$ & 122 & $18 \%$ & \\
\hline Gender $(\mathrm{N}=4,216)$ & & & & & & & 0.94 \\
\hline Female & 1,592 & $50 \%$ & 191 & $49 \%$ & 337 & $51 \%$ & \\
\hline Male & 1,572 & $50 \%$ & 195 & $51 \%$ & 329 & $49 \%$ & \\
\hline $\begin{array}{l}\text { HIV seropositive } \\
(\mathrm{N}=4,164)\end{array}$ & & & & & & & 0.52 \\
\hline No & 3,124 & $100 \%$ & 378 & $100 \%$ & 658 & $100 \%$ & \\
\hline Yes & 4 & $0 \%$ & 0 & $0 \%$ & 0 & $0 \%$ & \\
\hline $\begin{array}{l}\text { Diabetes Mellitus } \\
(\mathrm{N}=4,202)\end{array}$ & & & & & & & 0.07 \\
\hline No & 3,156 & $100 \%$ & 381 & $100 \%$ & 661 & $100 \%$ & \\
\hline Yes & 1 & $0 \%$ & 1 & $0 \%$ & 2 & $0 \%$ & \\
\hline $\begin{array}{l}\text { BCG scars } \\
(\mathrm{N}=4,216)\end{array}$ & & & & & & & 0.05 \\
\hline 0 & 593 & $19 \%$ & 90 & $23 \%$ & 141 & $21 \%$ & \\
\hline More than 1 & 2,571 & $81 \%$ & 296 & $77 \%$ & 525 & $79 \%$ & \\
\hline $\begin{array}{l}\text { Smoking status } \\
(\mathrm{N}=4,209)\end{array}$ & & & & & & & 0.84 \\
\hline
\end{tabular}




\begin{tabular}{|c|c|c|c|c|c|c|c|}
\hline $\begin{array}{l}\text { None or light } \\
\text { smoking }\end{array}$ & 3,139 & $99 \%$ & 382 & $99 \%$ & 663 & $100 \%$ & \\
\hline Heavy smoking & 20 & $1 \%$ & 2 & $1 \%$ & 3 & $0 \%$ & \\
\hline $\begin{array}{l}\text { Alcohol use } \\
(\mathrm{N}=4,195)\end{array}$ & & & & & & & 0.37 \\
\hline $\begin{array}{l}\text { None or light } \\
\text { drinker }\end{array}$ & 3,112 & $99 \%$ & 375 & $98 \%$ & 653 & $99 \%$ & \\
\hline Heavy drinker & 39 & $1 \%$ & 8 & $2 \%$ & 8 & $1 \%$ & \\
\hline $\begin{array}{l}\text { Nutritional status }{ }^{\dagger} \\
(\mathrm{N}=4,173)\end{array}$ & & & & & & & 0.98 \\
\hline Normal weight & 2,568 & $82 \%$ & 316 & $83 \%$ & 545 & $83 \%$ & \\
\hline Underweight & 77 & $2 \%$ & 10 & $3 \%$ & 16 & $2 \%$ & \\
\hline Overweight & 487 & $16 \%$ & 57 & $15 \%$ & 97 & $15 \%$ & \\
\hline $\begin{array}{l}\text { Use of public } \\
\text { transportation } \\
(\mathrm{N}=4,120)\end{array}$ & & & & & & & 0.34 \\
\hline Non-user & 1,159 & $37 \%$ & 135 & $36 \%$ & 237 & $37 \%$ & \\
\hline $\begin{array}{l}1 \text { to } 3 \text { days per } \\
\text { week }\end{array}$ & 994 & $32 \%$ & 137 & $37 \%$ & 218 & $34 \%$ & \\
\hline $\begin{array}{l}4 \text { to } 7 \text { days per } \\
\text { week }\end{array}$ & 952 & $31 \%$ & 100 & $27 \%$ & 188 & $29 \%$ & \\
\hline
\end{tabular}




\begin{tabular}{|c|c|c|c|c|c|c|c|}
\hline $\begin{array}{l}\text { Socioeconomic } \\
\text { status } \$(N=4,128)\end{array}$ & & & & & & & 0.85 \\
\hline Low & 1,210 & $39 \%$ & 144 & $39 \%$ & 268 & $40 \%$ & \\
\hline Middle & 1,369 & $44 \%$ & 166 & $45 \%$ & 283 & $43 \%$ & \\
\hline High & 520 & $17 \%$ & 55 & $15 \%$ & 113 & $17 \%$ & \\
\hline $\begin{array}{l}\text { TB infected at } \\
\text { baseline }(\mathrm{N}=4,068)\end{array}$ & & & & & & & 0.09 \\
\hline No & 2,214 & $72 \%$ & 256 & $68 \%$ & 441 & $69 \%$ & \\
\hline Yes & 842 & $28 \%$ & 118 & $32 \%$ & 197 & $31 \%$ & \\
\hline $\begin{array}{l}\text { TB history } \\
(\mathrm{N}=4,216)\end{array}$ & & & & & & & 0.49 \\
\hline No & 3,102 & $98 \%$ & 375 & $97 \%$ & 651 & $98 \%$ & \\
\hline Yes & 62 & $2 \%$ & 11 & $3 \%$ & 15 & $2 \%$ & \\
\hline $\begin{array}{l}\text { Employment } \\
(\mathrm{N}=4,214)\end{array}$ & & & & & & & 0.42 \\
\hline No & 2,917 & $92 \%$ & 351 & $91 \%$ & 606 & $91 \%$ & \\
\hline Yes & 245 & $8 \%$ & 35 & $9 \%$ & 60 & $9 \%$ & \\
\hline $\begin{array}{l}\text { Being a student } \\
(\mathrm{N}=4,214)\end{array}$ & & & & & & & 0.4 \\
\hline No & 1,137 & $36 \%$ & 141 & $37 \%$ & 258 & $39 \%$ & \\
\hline Yes & 2,025 & $64 \%$ & 245 & $63 \%$ & 408 & $61 \%$ & \\
\hline $\begin{array}{l}\text { Index-case age in } \\
\text { years }(N=4,216)\end{array}$ & & & & & & & 0.02 \\
\hline $16-30$ & 1,857 & $59 \%$ & 204 & $53 \%$ & 400 & $60 \%$ & \\
\hline 31 to 45 & 746 & $24 \%$ & 118 & $31 \%$ & 154 & $23 \%$ & \\
\hline 46 to 60 & 297 & $9 \%$ & 40 & $10 \%$ & 70 & $11 \%$ & \\
\hline$>60$ & 264 & $8 \%$ & 24 & $6 \%$ & 42 & $6 \%$ & \\
\hline
\end{tabular}




\begin{tabular}{|c|c|c|c|c|c|c|c|}
\hline $\begin{array}{l}\text { Index-case sex } \\
(\mathrm{N}=4,126)\end{array}$ & & & & & & & $<0.01$ \\
\hline Female & 1437 & $45 \%$ & 135 & $35 \%$ & 288 & $43 \%$ & \\
\hline Male & 1,727 & $55 \%$ & 251 & $65 \%$ & 378 & $57 \%$ & \\
\hline $\begin{array}{l}\text { Index-case smoking } \\
\text { status }(\mathrm{N}=4,125)\end{array}$ & & & & & & & $<0.01$ \\
\hline $\begin{array}{l}\text { None or light } \\
\text { smoker }\end{array}$ & 3,074 & $99 \%$ & 363 & $96 \%$ & 621 & $97 \%$ & \\
\hline Heavy smoker & 36 & $1 \%$ & 14 & $4 \%$ & 17 & $3 \%$ & \\
\hline $\begin{array}{l}\text { Index-case drinking } \\
\text { status }(N=4,053)\end{array}$ & & & & & & & 0.21 \\
\hline $\begin{array}{l}\text { None or light } \\
\text { drinker }\end{array}$ & 2,720 & $90 \%$ & 330 & $87 \%$ & 581 & $91 \%$ & \\
\hline Heavy drinker & 315 & $10 \%$ & 48 & $13 \%$ & 59 & $9 \%$ & \\
\hline $\begin{array}{l}\text { Index-case } \\
\text { employment } \\
(\mathrm{N}=4,200)\end{array}$ & & & & & & & 0.02 \\
\hline No & 2,104 & $67 \%$ & 233 & $61 \%$ & 459 & $69 \%$ & \\
\hline Yes & 1046 & $33 \%$ & 152 & $39 \%$ & 206 & $31 \%$ & \\
\hline $\begin{array}{l}\text { Index-case } \\
\text { Marijuana use } \\
(\mathrm{N}=4,206)\end{array}$ & & & & & & & 0.33 \\
\hline No & 2,760 & $87 \%$ & 327 & $85 \%$ & 573 & $87 \%$ & \\
\hline Yes & 399 & $13 \%$ & 59 & $15 \%$ & 88 & $13 \%$ & \\
\hline
\end{tabular}




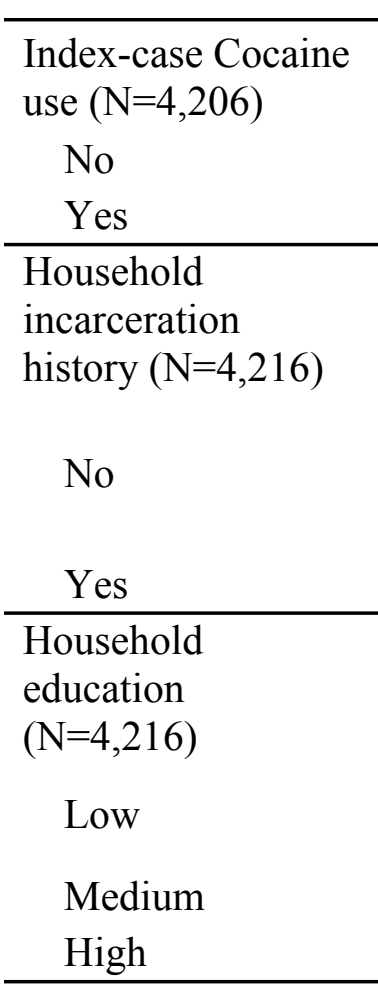

Household district $(\mathrm{N}=4,216)$

$2,643 \quad 84 \%$

$516 \quad 16 \%$

2,854

310

$10 \%$

$\begin{array}{cc}663 & 21 \% \\ 1814 & 57 \% \\ 687 & 22 \%\end{array}$

$\begin{array}{cc}77 & 20 \% \\ 191 & 49 \% \\ 118 & 31 \%\end{array}$

133

402

131

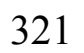

64

359

27

118
0.71

0.02

$<0.01$

$\begin{array}{lcccccc}\text { Cercado de Lima } & 276 & 9 \% & 46 & 12 \% & 51 & 8 \% \\ \text { Comas } & 214 & 7 \% & 20 & 5 \% & 13 & 2 \% \\ \text { El Agustino } & 229 & 7 \% & 18 & 5 \% & 99 & 15 \% \\ & & & & & & \\ \text { La Victoria } & 346 & 11 \% & 24 & 6 \% & 81 & 12 \%\end{array}$

$<0.01$

$20 \%$

$20 \%$ 


\begin{tabular}{lcccccc} 
Los Olivos & 332 & $10 \%$ & 39 & $10 \%$ & 79 & $12 \%$ \\
Rimac & 310 & $10 \%$ & 60 & $16 \%$ & 37 & $6 \%$ \\
$\begin{array}{l}\text { San Martin de } \\
\text { Porres }\end{array}$ & 713 & $23 \%$ & 97 & $25 \%$ & 168 & $25 \%$ \\
Santa Anita & 186 & $6 \%$ & 7 & $2 \%$ & 28 & $4 \%$ \\
Others & 558 & $18 \%$ & 75 & $19 \%$ & 110 & $17 \%$ \\
\hline${ }^{*}$ Compared the two groups used a $\chi^{2}$ test &
\end{tabular}

${ }^{\dagger}$ Nutritional status was defined by the WHO body mass index z-score tables

$\$$ Socioeconomic status was defined using a principal component analysis based on housing quality, water supply, and sanitation.

Abbreviation: N: number; TB: tuberculosis; isoniazid: isoniazid; isoniazid preventive therapy: isoniazid prevention therapy; MDR: multi-drug resistant 
Table 2. Baseline characteristics of household contacts $\leq 19$ years old, stratified by isoniazid prevention therapy.

\begin{tabular}{|c|c|c|c|c|c|}
\hline \multirow[t]{2}{*}{ Characteristic } & \multicolumn{2}{|c|}{$\begin{array}{c}\text { No Isoniazid } \\
\text { preventive } \\
\text { therapy } \\
\end{array}$} & \multicolumn{2}{|c|}{$\begin{array}{c}\text { Isoniazid } \\
\text { preventive } \\
\text { therapy } \\
\end{array}$} & \multirow[t]{2}{*}{$\begin{array}{c}\mathrm{p}- \\
\text { value* }\end{array}$} \\
\hline & $\mathrm{N}$ & $\%$ & $\mathrm{~N}$ & $\%$ & \\
\hline Age in years $(\mathrm{N}=4,216)$ & & & & & $<0.01$ \\
\hline 0 to 5 & 664 & $31 \%$ & 855 & $41 \%$ & \\
\hline 6 to 10 & 439 & $21 \%$ & 532 & $25 \%$ & \\
\hline 11 to 15 & 489 & $23 \%$ & 451 & $22 \%$ & \\
\hline 16 to 19 & 528 & $25 \%$ & 258 & $12 \%$ & \\
\hline Gender $(\mathrm{N}=4,216)$ & & & & & 0.21 \\
\hline Female & 1,087 & $51 \%$ & 1,033 & $49 \%$ & \\
\hline Male & 1,033 & $49 \%$ & 1,063 & $51 \%$ & \\
\hline \multicolumn{6}{|l|}{ HIV seropositive $(\mathrm{N}=4,164)$} \\
\hline No & 2,086 & $100 \%$ & 2,074 & $100 \%$ & 0.14 \\
\hline Yes & 4 & $0 \%$ & 0 & $0 \%$ & \\
\hline \multicolumn{6}{|l|}{ Diabetes Mellitus $(\mathrm{N}=4,202)$} \\
\hline No & 2,111 & $100 \%$ & 2,087 & $100 \%$ & 0.99 \\
\hline Yes & 2 & $0 \%$ & 2 & $0 \%$ & \\
\hline \multicolumn{6}{|l|}{ BCG scars $(\mathrm{N}=4,216)$} \\
\hline 0 & 423 & $20 \%$ & 401 & $19 \%$ & 0.39 \\
\hline$>1$ & 1,697 & $80 \%$ & 1,695 & $81 \%$ & \\
\hline \multicolumn{6}{|l|}{ Smoking status $(\mathrm{N}=4,209)$} \\
\hline$\leq 1$ cigarette per day & 2,093 & $99 \%$ & 2,091 & $100 \%$ & $<0.01$ \\
\hline$>1$ cigarette per day & 22 & $1 \%$ & 3 & $0 \%$ & \\
\hline \multicolumn{6}{|l|}{ Alcohol use $(\mathrm{N}=4,195)$} \\
\hline$<3$ drinks per day & 2,061 & $98 \%$ & 2,079 & $99 \%$ & $<0.01$ \\
\hline$\geq 3$ drinks per day & 44 & $2 \%$ & 11 & $1 \%$ & \\
\hline \multicolumn{6}{|l|}{ Nutritional status ${ }^{\dagger}(\mathrm{N}=4,173)$} \\
\hline Normal weight & 1,748 & $83 \%$ & 1,681 & $81 \%$ & 0.12 \\
\hline Underweight & 44 & $2 \%$ & 59 & $3 \%$ & \\
\hline Overweight & 308 & $15 \%$ & 333 & $16 \%$ & \\
\hline $\begin{array}{l}\text { Use of public transportation } \\
(\mathrm{N}=4,120)\end{array}$ & & & & & 0.02 \\
\hline Non-user & 736 & $35 \%$ & 795 & $39 \%$ & \\
\hline 1 to 3 days per week & 709 & $34 \%$ & 640 & $32 \%$ & \\
\hline 4 to 7 days per week & 652 & $31 \%$ & 588 & $29 \%$ & \\
\hline Socioeconomic status $\$(N=4,128)$ & & & & & 0.20 \\
\hline
\end{tabular}




\begin{tabular}{|c|c|c|c|c|c|}
\hline Low & 821 & $40 \%$ & 801 & $39 \%$ & \\
\hline Middle & 931 & $45 \%$ & 887 & $43 \%$ & \\
\hline High & 325 & $16 \%$ & 363 & $18 \%$ & \\
\hline TB infected at baseline $(\mathrm{N}=4,068)$ & & & & & 0.01 \\
\hline No & 1,417 & $70 \%$ & 1,494 & $73 \%$ & \\
\hline Yes & 613 & $30 \%$ & 544 & $27 \%$ & \\
\hline TB history $(\mathrm{N}=4,216)$ & & & & & $<0.01$ \\
\hline No & 2,042 & $96 \%$ & 2,086 & $100 \%$ & \\
\hline Yes & 78 & $4 \%$ & 10 & $0 \%$ & \\
\hline Employment $(\mathrm{N}=4,214)$ & & & & & $<0.01$ \\
\hline No & 1,893 & $89 \%$ & 1,981 & $95 \%$ & \\
\hline Yes & 226 & $11 \%$ & 114 & $5 \%$ & \\
\hline Being a student $(\mathrm{N}=4,214)$ & & & & & 0.02 \\
\hline No & 809 & $38 \%$ & 727 & $35 \%$ & \\
\hline Yes & 1,311 & $62 \%$ & 1,367 & $65 \%$ & \\
\hline Index-case age in years $(\mathrm{N}=4,216)$ & & & & & $<0.01$ \\
\hline $16-30$ & 1,264 & $60 \%$ & 1,197 & $57 \%$ & \\
\hline 31 to 45 & 438 & $21 \%$ & 580 & $28 \%$ & \\
\hline 46 to 60 & 252 & $12 \%$ & 155 & $7 \%$ & \\
\hline$>60$ & 166 & $8 \%$ & 164 & $8 \%$ & \\
\hline Index-case sex $(\mathrm{N}=4,126)$ & & & & & $<0.01$ \\
\hline Female & 836 & $39 \%$ & 1,024 & $49 \%$ & \\
\hline Male & 1,284 & $61 \%$ & 1,072 & $51 \%$ & \\
\hline $\begin{array}{l}\text { Index-case smoking status } \\
(\mathrm{N}=4,125)\end{array}$ & & & & & 0.45 \\
\hline None or light smoker & 2,037 & $99 \%$ & 2,021 & $98 \%$ & \\
\hline Heavy smoker & 30 & $1 \%$ & 37 & $2 \%$ & \\
\hline $\begin{array}{l}\text { Index-case drinking status } \\
(\mathrm{N}=4,053)\end{array}$ & & & & & 0.25 \\
\hline None or light drinker & 1,798 & $89 \%$ & 1,833 & $90 \%$ & \\
\hline Heavy drinker & 222 & $11 \%$ & 200 & $10 \%$ & \\
\hline Index-case employment $(\mathrm{N}=4,200)$ & & & & & 0.62 \\
\hline No & 1,412 & $67 \%$ & 1,384 & $66 \%$ & \\
\hline Yes & 697 & $33 \%$ & 707 & $34 \%$ & \\
\hline $\begin{array}{l}\text { Index-case Isoniazid-profile } \\
(\mathrm{N}=4,216)\end{array}$ & & & & & $<0.01$ \\
\hline Sensitive & 1,534 & $72 \%$ & 1,630 & $78 \%$ & \\
\hline Mono-resistant & 185 & $9 \%$ & 201 & $10 \%$ & \\
\hline MDR & 401 & $19 \%$ & 265 & $13 \%$ & \\
\hline Index-case Marijuana use $(\mathrm{N}=4,206)$ & & & & & $<0.01$ \\
\hline
\end{tabular}




\begin{tabular}{|c|c|c|c|c|c|}
\hline No & 1,774 & $84 \%$ & 1,811 & $90 \%$ & \\
\hline Yes & 336 & $16 \%$ & 284 & $10 \%$ & \\
\hline Index-case Cocaine use $(\mathrm{N}=4,206)$ & & & & & $<0.01$ \\
\hline No & 1,715 & $81 \%$ & 1,811 & $86 \%$ & \\
\hline Yes & 396 & $19 \%$ & 284 & $14 \%$ & \\
\hline $\begin{array}{l}\text { Household incarceration history } \\
(\mathrm{N}=4,216)\end{array}$ & & & & & $<0.01$ \\
\hline No & 1,863 & $88 \%$ & 1,943 & $92 \%$ & \\
\hline Yes & 257 & $12 \%$ & 162 & $8 \%$ & \\
\hline Household education $(\mathrm{N}=4,216)$ & & & & & $<0.01$ \\
\hline Low & 900 & $42 \%$ & 1,384 & $34 \%$ & \\
\hline Medium & 801 & $38 \%$ & 707 & $41 \%$ & \\
\hline High & 419 & $20 \%$ & 1,384 & $25 \%$ & \\
\hline Household district $(\mathrm{N}=4,216)$ & & & & & 0.62 \\
\hline Cercado de Lima & 238 & $11 \%$ & 135 & $6 \%$ & \\
\hline Comas & 112 & $5 \%$ & 135 & $6 \%$ & \\
\hline El Agustino & 294 & $14 \%$ & 52 & $2 \%$ & \\
\hline La Victoria & 273 & $13 \%$ & 178 & $8 \%$ & \\
\hline Los Olivos & 212 & $10 \%$ & 238 & $11 \%$ & \\
\hline Rimac & 84 & $4 \%$ & 323 & $15 \%$ & \\
\hline San Martin de Porres & 373 & $18 \%$ & 605 & $29 \%$ & \\
\hline Santa Anita & 138 & $7 \%$ & 83 & $4 \%$ & \\
\hline Others & 396 & $19 \%$ & 347 & $17 \%$ & \\
\hline
\end{tabular}

* Compared the two groups used a $\chi^{2}$ test

$\dagger$ Nutritional status was defined by the WHO body mass index z-score tables

$\$$ Socioeconomic status was defined using a principal component analysis based on housing quality, water supply, and sanitation.

Abbreviation: N: number; TB: tuberculosis; isoniazid: isoniazid; isoniazid preventive therapy: isoniazid prevention therapy; MDR: multi-drug resistant 
Table 3. The effect of isoniazid prevention therapy on disease incidence of children $\leq$ five years of age, stratified by isoniazid profiles of index cases; adjusted for index case age, recreational drug use, household contact age, gender, BCG-vaccination scar, nutritional status, being a student or not, tuberculosis history, household socioeconomic status, and household residential district.

A. Complete dataset

\begin{tabular}{|c|c|c|c|c|c|c|}
\hline \multirow{2}{*}{$\begin{array}{l}\text { Isoniazid } \\
\text { prevention } \\
\text { therapy }\end{array}$} & \multicolumn{2}{|c|}{ Isoniazid-sensitive } & \multicolumn{2}{|c|}{ MDR } & \multicolumn{2}{|c|}{ Mono-isoniazid resistant } \\
\hline & Cases/Person-year & $\operatorname{HR}(95 \% \mathrm{CI})$ & Cases/Person-year & $\operatorname{HR}(95 \% \mathrm{CI})$ & Cases/Person-year & $\operatorname{HR}(95 \% \mathrm{CI})$ \\
\hline No & $19 / 566$ & Ref & $10 / 145$ & Ref & $3 / 58$ & Ref \\
\hline Yes & $9 / 785$ & $0.28(0.12-0.58)$ & $2 / 144$ & $0.19(0.04-0.98)$ & $1 / 90$ & $0.25(0.02-2.76)$ \\
\hline
\end{tabular}

Likelihood ratio test for interaction term: 0.413

B. Household contacts who received isoniazid prevention therapy $\geq$ three months

\begin{tabular}{|c|c|c|c|c|c|c|}
\hline \multirow{2}{*}{$\begin{array}{l}\text { Isoniazid } \\
\text { prevention } \\
\text { therapy }\end{array}$} & \multicolumn{2}{|c|}{ Isoniazid-sensitive } & \multicolumn{2}{|c|}{ MDR } & \multicolumn{2}{|c|}{ Mono-isoniazid resistant } \\
\hline & Cases/Person-year & $\operatorname{HR}(95 \% \mathrm{CI})$ & Cases/Person-year & $\mathrm{HR}(95 \% \mathrm{CI})$ & Cases/Person-year & $\operatorname{HR}(95 \% \mathrm{CI})$ \\
\hline No & $19 / 566$ & Ref & $10 / 145$ & Ref & $3 / 58$ & Ref \\
\hline Yes & $1 / 470$ & $\begin{array}{c}0.06(0.01 \text { to } \\
0.43)\end{array}$ & $0 / 54$ & 0 (0-infinity) & $0 / 64$ & 0 (0-infinity) \\
\hline
\end{tabular}

Likelihood ratio test for interaction term: 0.768

C. Household contacts who received isoniazid prevention therapy $<$ three months

\begin{tabular}{|c|c|c|c|c|c|c|}
\hline \multirow{2}{*}{$\begin{array}{l}\text { Isoniazid } \\
\text { prevention } \\
\text { therapy }\end{array}$} & \multicolumn{2}{|c|}{ Isoniazid-sensitive } & \multicolumn{2}{|c|}{ MDR } & \multicolumn{2}{|c|}{ Mono-isoniazid resistant } \\
\hline & Cases/Person-year & $\mathrm{HR}(95 \% \mathrm{CI})$ & Cases/Person-year & $\mathrm{HR}(95 \% \mathrm{CI})$ & Cases/Person-year & $\operatorname{HR}(95 \% \mathrm{CI})$ \\
\hline No & $19 / 566$ & Ref & $10 / 145$ & Ref & $3 / 58$ & Ref \\
\hline Yes & $10 / 273$ & $1.49(0.5-4.44)$ & $1 / 77$ & $0.38(0.04-3.46)$ & $1 / 42$ & $2.04(0.14-29.64)$ \\
\hline
\end{tabular}

Likelihood ratio test for interaction term: 0.158 


\section{Univariate \\ $(\mathrm{N}=4,216)$ \\ $0.33(0.22-0.48)$}

Multivariate

$(\mathrm{N}=4,075)$

$$
0.31(0.20-0.47)
$$

\begin{tabular}{|c|c|c|c|}
\hline & $T$ & $T$ & $T$ \\
\hline 0.2 & 0.4 & 0.6 & 0.8 \\
\hline
\end{tabular}




\section{Events/N}

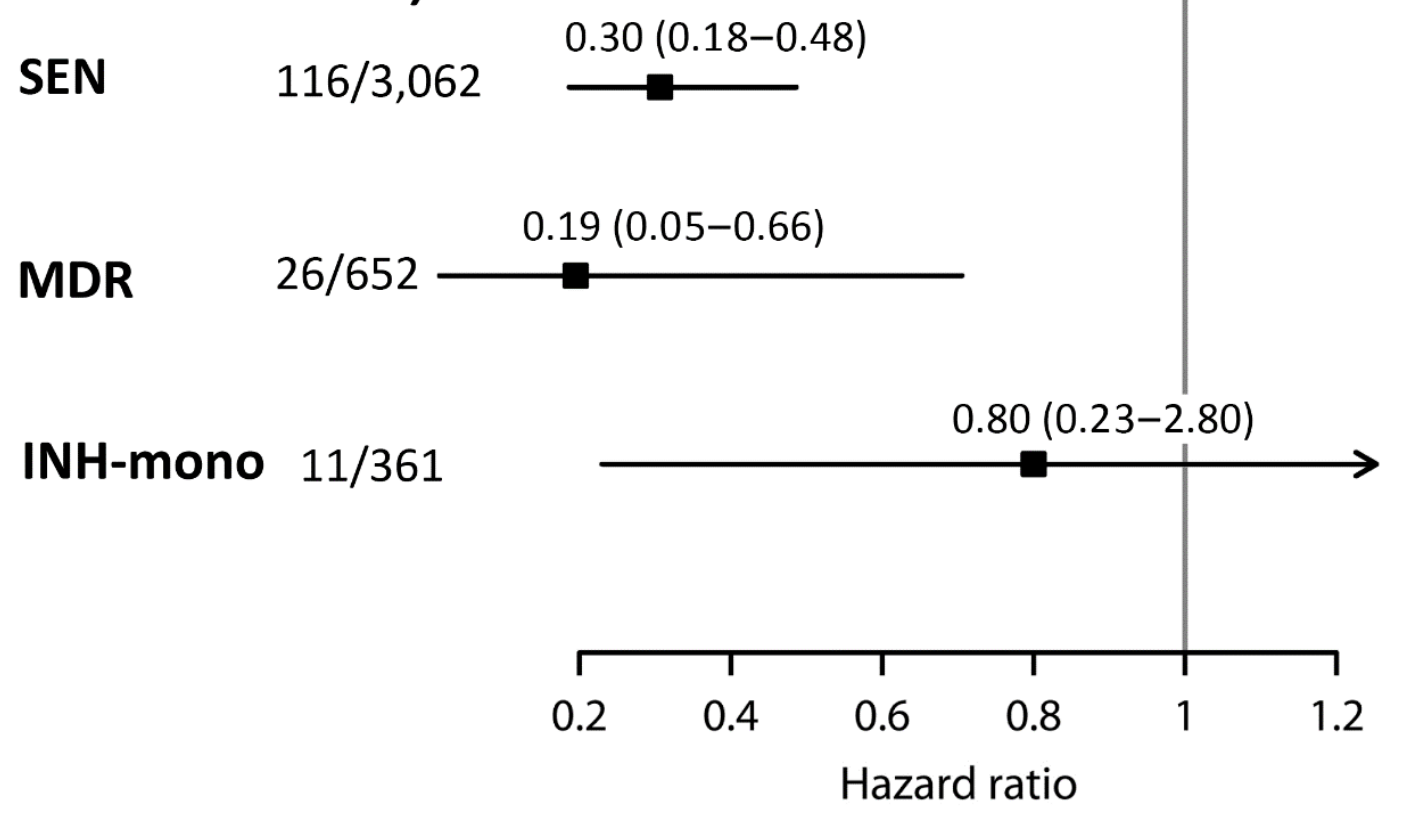




\section{A. $\geq 3$ months}

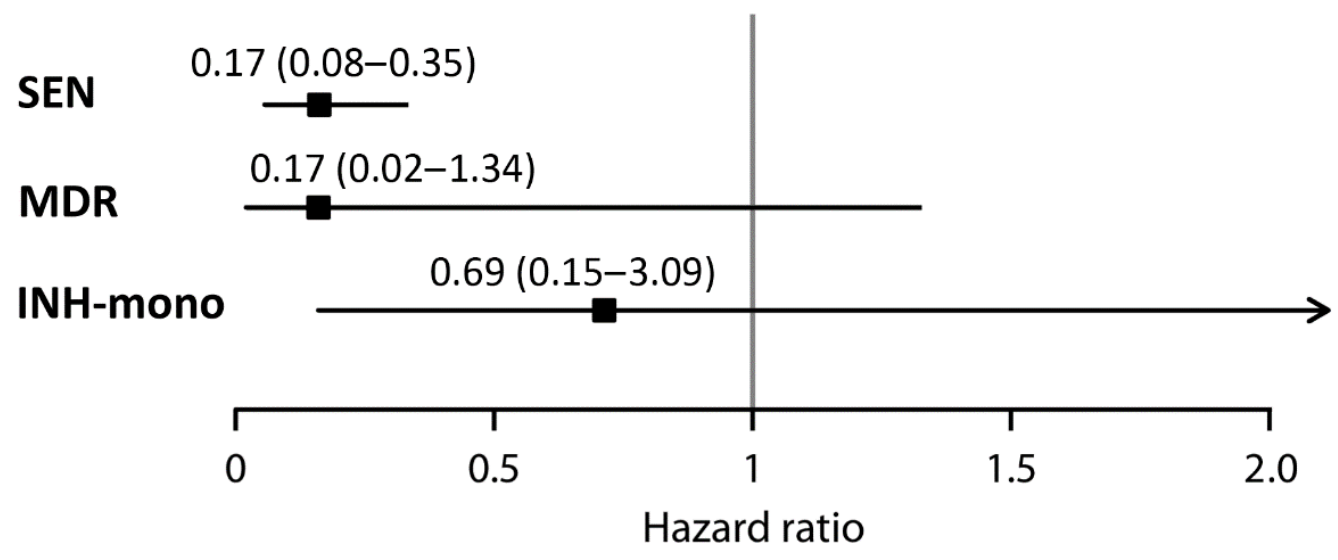

\section{B. $<3$ months}

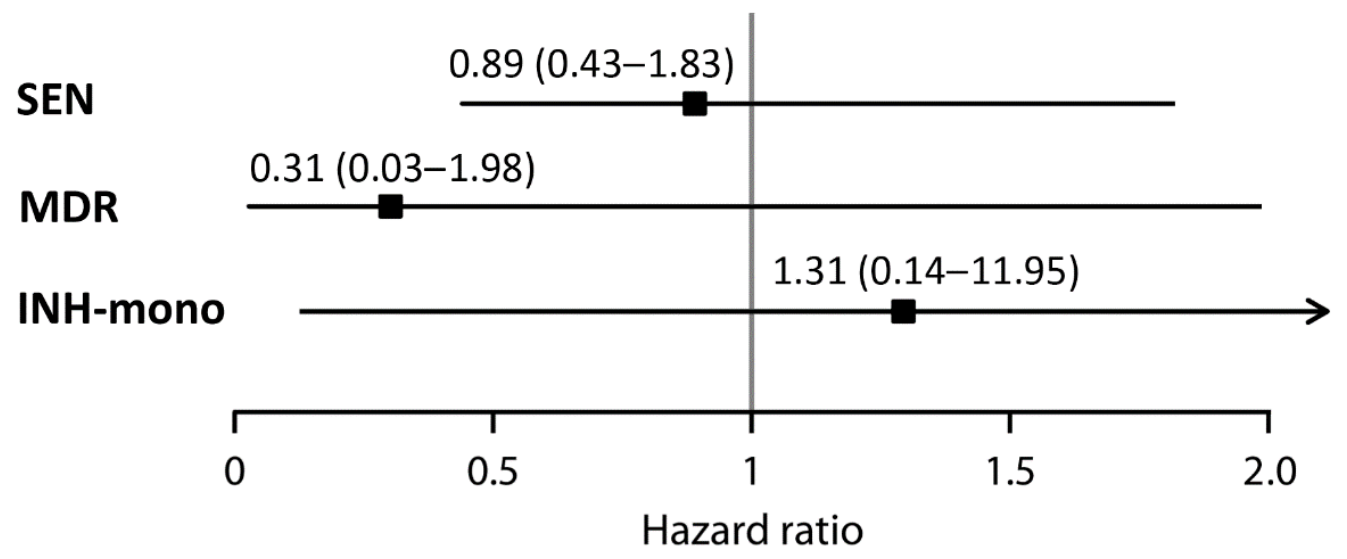




\section{Supplementary Appendix}

\section{Table of Contents}

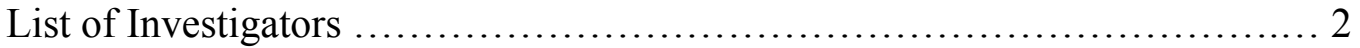

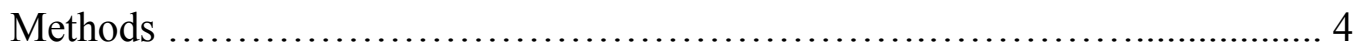

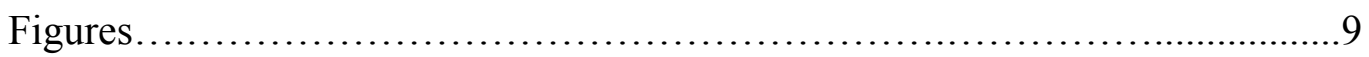

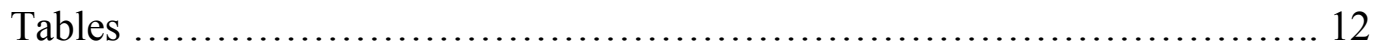

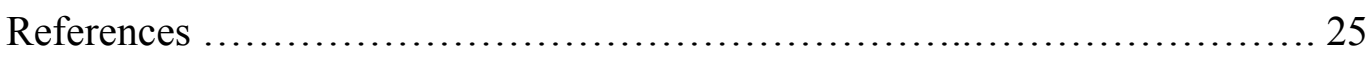




\section{List of Investigators}

1. Chuan-Chin Huang, Sc.D., Brigham and Women's Hospital, Division of Global Health Equity, 75 Francis Street, Boston, Massachusetts 02115, United States; Department of Global Health and Social Medicine, Harvard Medical School, 641 Huntington Avenue, Boston, Massachusetts 02115, United States.

2. Mercedes C. Becerra, Sc.D., Department of Global Health and Social Medicine, Harvard Medical School, 641 Huntington Avenue, Boston, Massachusetts 02115, United States.

3. Roger Calderon, M.S., Partners in Health - Socios En Salud Sucursal, Av. Chimpu Ocllo \# 998 Urb. Residencial Lucyana, Carabayllo, Lima, Peru.

4. Carmen Contreras, M.P.H., Partners in Health - Socios En Salud Sucursal, Av. Chimpu Ocllo \# 998 Urb. Residencial Lucyana, Carabayllo, Lima, Peru.

5. Jerome Galea, Ph.D., School of Social Work, University of South Florida, 13301 Bruce B Downs Blvd, MHC 1416 A, Tampa, Florida 33612, USA

6. Louis Grandjean, Ph.D., Wellcome Centre for Clinical Tropical Medicine, Imperial College London, London WC1H 9JJ, United Kingdom ; Universidad Peruana Cayetano Heredia, Av. Honorio Delgado 430, Urb Ingeniería, Lima, Peru; TB Centre, London School of Hygiene \& Tropical Medicine, Keppel Street, London WC1E 7HT, United Kingdom.

7. Leonid Lecca, M.D., Partners in Health - Socios En Salud Sucursal, Av. Chimpu Ocllo \# 998 Urb. Residencial Lucyana, Carabayllo, Lima, Peru.

8. Rosa Yataco, Partners in Health - Socios En Salud Sucursal, Av. Chimpu Ocllo \# 998 Urb. Residencial Lucyana, Carabayllo, Lima, Peru. 
9. Zibiao Zhang, M.S., Brigham and Women's Hospital, Division of Global Health Equity, 75 Francis Street, Boston, Massachusetts 02115, United States.

10. Megan Murray, M.D., Sc.D., Harvard Medical School, Department of Global Health and Social Medicine, Boston, Massachusetts, United States and Brigham and Women's Hospital, Division of Global Health Equity, Boston, Massachusetts, United States 


\section{Methods}

\section{Recruitment}

This study was conducted in Lima in 106 district health centers that provide care to a population of approximately three million residents. We enrolled all patients who were newly diagnosed with pulmonary tuberculosis and over 15 years of age. The diagnosis was performed by a health center clinician on the basis of sputum smear microscopy or chest radiography. We collected an additional sputum sample from consenting participants which we sent for repeat sputum smear microscopy, mycobacterial culture, and drug sensitivity testing. We confirmed the microbiological status of their pulmonary tuberculosis disease with either a positive sputum smear or mycobacterial culture. We requested permission to visit each patient's household and recruit his or her household contacts (household contacts) into a prospective cohort study. Study workers aimed to enroll all household members within one week of the diagnosis of the index case.

\section{Baseline assessment of index patients}

We collected the following data from index patients at the time of enrollment: age, gender, occupation, symptoms of tuberculosis, duration of symptoms, history of tuberculosis disease, alcohol, intravenous drug, recreational drug, and tobacco history, and comorbidities including HIV and diabetes mellitus. Patients who did not know their HIV status had blood drawn for HIV and CD4 count. Signs associated with tuberculosis disease, height, and weight were recorded. Index patients also underwent HIV testing and were evaluated with a chest radiograph. The time to treatment was measured as the number of days the patient reported coughing prior to diagnosis.

\section{Bacteriological cultures and drug susceptibility testing}

Sputum samples were tested for the presence of acid-fast bacilli by Ziehl-Neelsen staining and cultured by inoculation in two tubes containing Lowenstein-Jensen or Ogawa medium. Indirect susceptibility testing to isoniazid, Rifampicin (RIF), Ethambutol (EMB) and Streptomycin (STR) was conducted by the Löwenstein-Jensen Proportion Method, using the following drug concentrations: isoniazid (0.2 and $1.0 \mu \mathrm{g} / \mathrm{ml})$, RIF $(40.0 \mu \mathrm{g} / \mathrm{ml})$, EMB $(2.0 \mu \mathrm{g} / \mathrm{ml})$, and STR $(4.0$ $\mu \mathrm{g} / \mathrm{ml})$. Susceptibility to Pyrazinamide (PZA) $(100 \mathrm{ug} / \mathrm{ml})$ was tested using the Wayne method. DNA from each mycobacterial culture was extracted and genotyped by 24-loci mycobacterial interspersed repetitive units-variable-number tandem repeats (MIRU-VNTR) using standard methods (1).

\section{Whole genome sequencing on culture positive isolates}

Mtb strains were sequenced on an Illumina Hiseq 4000 in paired-end mode with a read-length of 100-150 base-pairs (bps) and at least a 50-fold coverage (2). The paired-end raw sequence data were mapped to the H37Rv reference genome using the BWA mem algorithm (3). We used SAMtools (default settings) and pilon to identify the single nucleotide polymorphisms (SNPs) across the whole genome using a coverage-based approach $(4,5)$. We assigned a call as missing if the valid depth of coverage at a specific site is less than 10 reads, if the mean read mapping 
quality at the site does not reach 7 , or if none of the alternative alleles account for at least $90 \%$ of the valid coverage.

\section{Follow-up of index patients}

Index patients received directly observed therapy at their district health clinics, as specified in the Peruvian National Tuberculosis Control Program (NTP) guidelines for drug-sensitive and drug-resistant tuberculosis. Patients with drug-sensitive tuberculosis received a standard 6-month course with a 2-month "intensification phase" of isoniazid, RIF, PZA, and EMB followed by a 4month "consolidation phase" of isoniazid and RIF alone. Patients with MDR-tuberculosis, received treatment according to NTP guidelines. Since results for routine drug resistance testing were often not available for two to three months after initial diagnosis, patients who were not previously suspected of having MDR-tuberculosis, were started on a first-line drug regimen until MDR-tuberculosis, was confirmed.

\section{Isoniazid preventive therapy for household contacts}

The 2006 Peruvian National tuberculosis Program recommended that household contacts 19 years old or younger and those who had a specified comorbidity should receive six months of isoniazid preventive therapy while those with HIV should receive 12 months (6). Children aged 19 and under were offered isoniazid preventive therapy at the time index patients were diagnosed, regardless of tuberculin skin test (TST) status. Health care providers often chose to discontinue isoniazid preventive therapy in household contacts if the index patient was subsequently diagnosed with MDR-tuberculosis, but some MDR-exposed household contacts received a full course of isoniazid preventive therapy. We used medical records from participating hospitals and health clinics to determine the duration of isoniazid preventive therapy.

\section{Enrollment of household contacts}

At the time of the enrollment of household contacts, study workers collected the following data: whether isoniazid preventive therapy had been initiated, age, gender, relationship to index patient, housing information including number of rooms, building material, type of flooring, education, residential district, history of incarceration, occupation, alcohol, cigarette and illicit drug intake, general health history including previous history of tuberculosis, BCG vaccination, co-morbidities, BMI medications taken. Participants were assessed for symptoms associated with tuberculosis disease including cough, night sweats, weight loss, and fever. Those with symptoms were referred to their local health clinic for chest radiography and clinical evaluation for active tuberculosis disease. Household members with no known history of active tuberculosis disease or previously documented infection received a TST, and those with unknown HIV status were tested for HIV. 


\section{Follow-up of household contacts}

Participants were revisited in their household at two, six, and 12 months and were asked whether they had been diagnosed with tuberculosis or if they had had symptoms of active disease. Those who reported symptoms were referred to their local health center for further clinical evaluation including a chest radiograph and sputum smear. Participants who tested negative at the initial study visit and who had not developed active tuberculosis disease at the time of the follow-up visit underwent repeat TST and clinical evaluation at six and 12 months. We used medical records from participating hospitals and health clinics to determine the duration of isoniazid preventive therapy.

\section{Data categorization}

We considered household contacts to have received isoniazid preventive therapy in response to the exposure to the index patient if isoniazid was initiated within three months of that patient's diagnosis. We categorized participants according to their alcohol intake as nondrinkers if they reported having consumed no alcoholic drinks per day, light drinkers if they reported drinking $<40$ grams or $<3$ alcoholic drinks per day, and heavy drinkers if they reported drinking 40 grams or more of alcohol or three or more drinks per day. A large proportion of smokers reported smoking only a single cigarette per day. We classified people as nonsmokers if they reported no cigarette smoking, as light smokers if they reported smoking one cigarette per day, and as heavy smokers if they reported smoking more than one cigarette per day. We defined nutritional status for children based on the WHO body mass index (BMI) z-score tables (7). We assigned people with BMI z-scores of less than two as underweight and those greater than two as overweight.

We created a continuous variable to capture household socioeconomic status (SES) by including variables on housing quality, water supply, and sanitation in a principal component analysis (PCA). PCA is a data reduction statistical technique that extracts a set of uncorrelated 'principal components' from a set of correlated variables, where each principal component is a weighted linear combination of the original variables. The continuous SES score was categorized into tertiles corresponding to relative "low," "middle," and "upper" SES. We categorized household average education into "low," "middle," and "upper" levels.

\section{Outcome definition}

We identified incident tuberculosis among household contacts during scheduled household visits and from a systematic review of tuberculosis registries at the participating health clinics to ensure we obtained all the incident tuberculosis among household contacts during the one-year follow-up. We considered household contacts to have co-prevalent tuberculosis if they were diagnosed within two weeks of the diagnosis of the index case. If household contacts were diagnosed between two weeks and 15 months after diagnosis of the index case, we considered them "secondary" cases. Diagnosis of adult secondary tuberculosis followed the same criteria as outlined above for index cases. We defined secondary tuberculosis disease among contacts younger than 18 years of age according to the consensus guidelines for classifying tuberculosis disease in children (8). 


\section{Analyses}

We included in our analysis only household contacts under 19 because older contacts were only offered isoniazid preventive therapy if they had comorbidities that substantially increased their risk of tuberculosis disease. We used a Cox frailty proportional hazards model to evaluate risk factors for incident tuberculosis disease, accounting for clustering within households (9). We first performed a univariate analysis to examine the effect of isoniazid preventive therapy on tuberculosis incidence, followed by a multivariate model in which we adjusted for the age of the index case age and the age, SES and tuberculosis history of the household contact. To evaluate whether the effect of isoniazid preventive therapy on tuberculosis incidence varied by resistance profile of the index case, we added a variable representing isoniazid resistance in the index case and an interaction term for isoniazid-resistance and isoniazid preventive therapy. Because the spectrum of isoniazid resistance-causing mutations that lead to isoniazid mono-resistance may differ from those that lead to MDR-tuberculosis, we classified strains as sensitive, monoisoniazid-resistant, or MDR-tuberculosis, (resistant to both isoniazid and RIF). Previous studies have shown that the efficacy of isoniazid preventive therapy treatment is reduced if the treatment is ended within three months (10). We therefore repeated these analyses stratifying by a dichotomous variable that captured treatment for more or less than three months. We also considered the possibility that household contacts $\leq 5$ years of age would be more likely to acquire tuberculosis at home than in the community compared to older contacts and we thus conducted sensitivity analyses restricted to this subgroup.

To determine whether the effect of isoniazid preventive therapy on disease in the household contacts was a function of the mean inhibitory concentrations (MICs) of the infecting organism, we repeated these analyses for the subset of household contacts exposed to index cases for whom quantitative isoniazid-resistance was available.

\section{Verifying our finding with an independent dataset}

We conducted a similar analysis using publically available data from an independent dataset collected from a prospective cohort study in South Lima and Callao, Peru between 2010 and 2013, posted by Grandjean et al. (11). This study enrolled 1,055 household contacts of 213 MDR-tuberculosis, index cases and 2,362 household contacts of 487 drug-susceptible index cases and measured incident tuberculosis over 2-years of follow-up. Drug susceptibility testing for isoniazid and RIF was performed for all index cases' samples using microscopic observation drug susceptibility assays in regional laboratories and results were confirmed in the national reference laboratory using proportions methods (12). The investigators note that isoniazid preventive therapy was discontinued in this group after MDR-tuberculosis, index cases were confirmed but data on the duration of isoniazid preventive therapy were not available.

We used a Cox frailty proportional hazards model to evaluate the association between isoniazid preventive therapy and incident tuberculosis infection in individuals aged 19 and under, accounting for clustering within each matched set. We first performed univariate analysis, followed by a multivariate model adjusted for household contacts' age, SES, and previous tuberculosis history. We then added a dichotomous variable for the drug resistance status (MDR 
or sensitive) in the index case, as well as interaction terms for the resistance profile and isoniazid preventive therapy to evaluate whether the effect of isoniazid preventive therapy on tuberculosis incidence varied by the resistance profile of index cases. 
Figure S1. Flow diagram of household contacts of household contacts of index tuberculosis patients

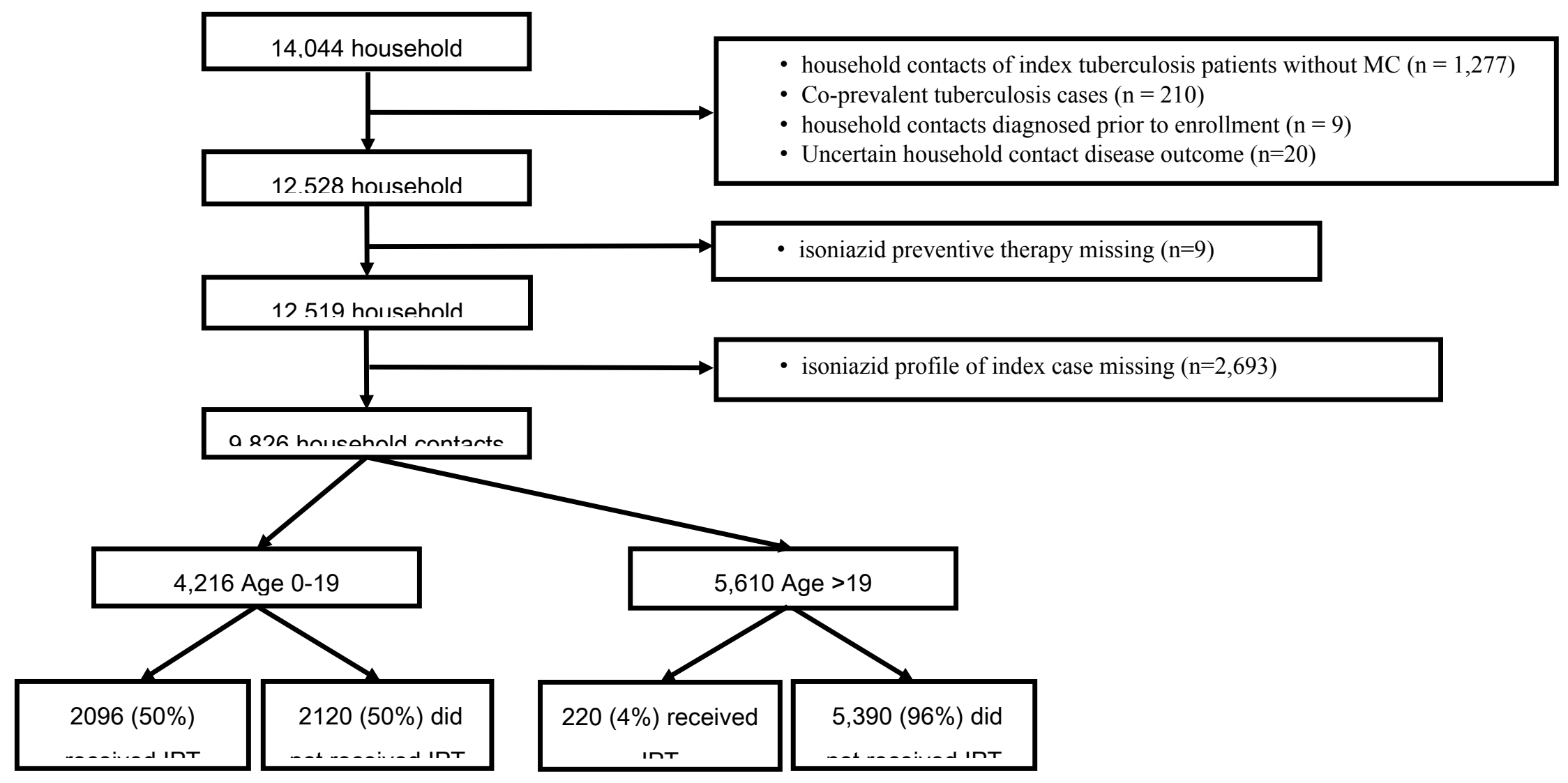


Figure S2. Duration of isoniazid prevention therapy by isoniazid resistant profile pattern of tuberculosis index cases

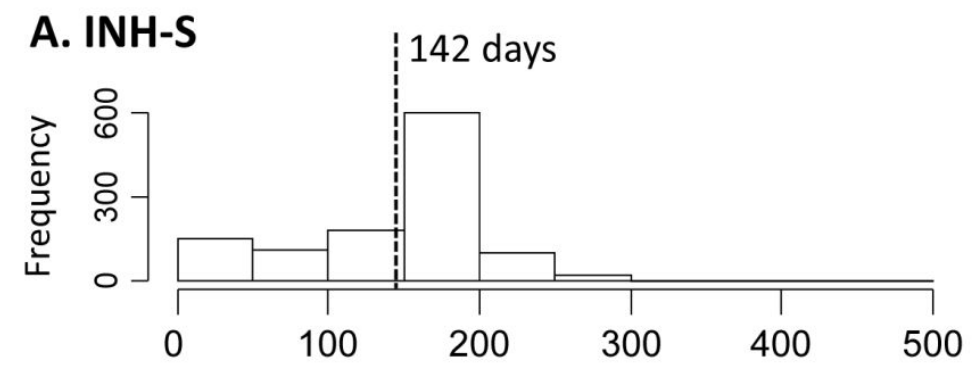

\section{B. MDR}

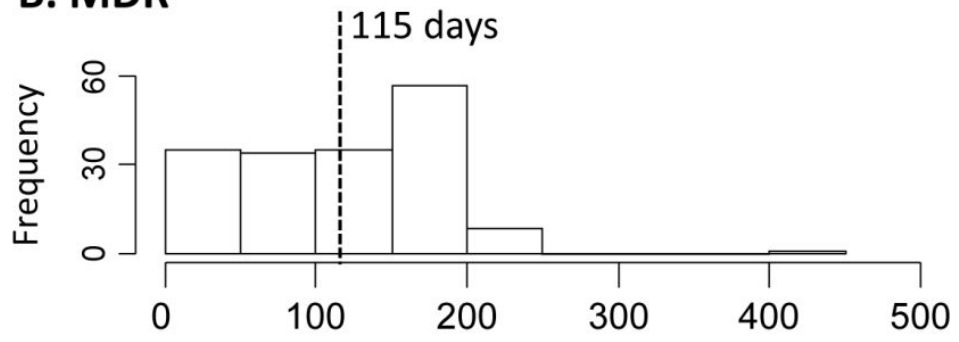

\section{INH-mono}

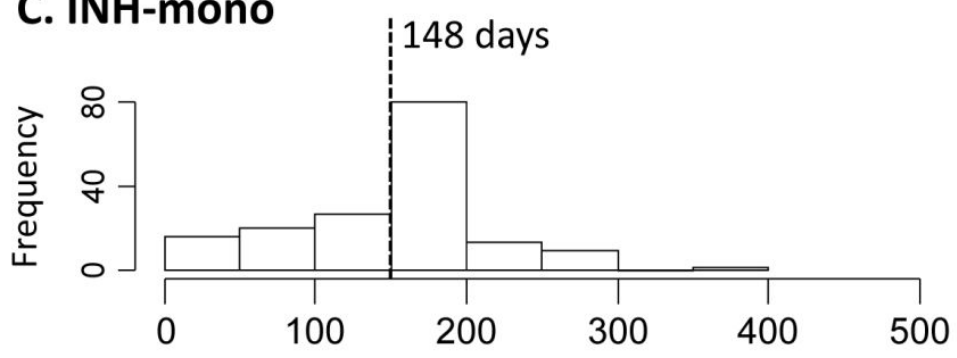


Figure S3. Genetic distance of secondary cases and their index cases

\section{Genetic distance of HHC/Index_case}

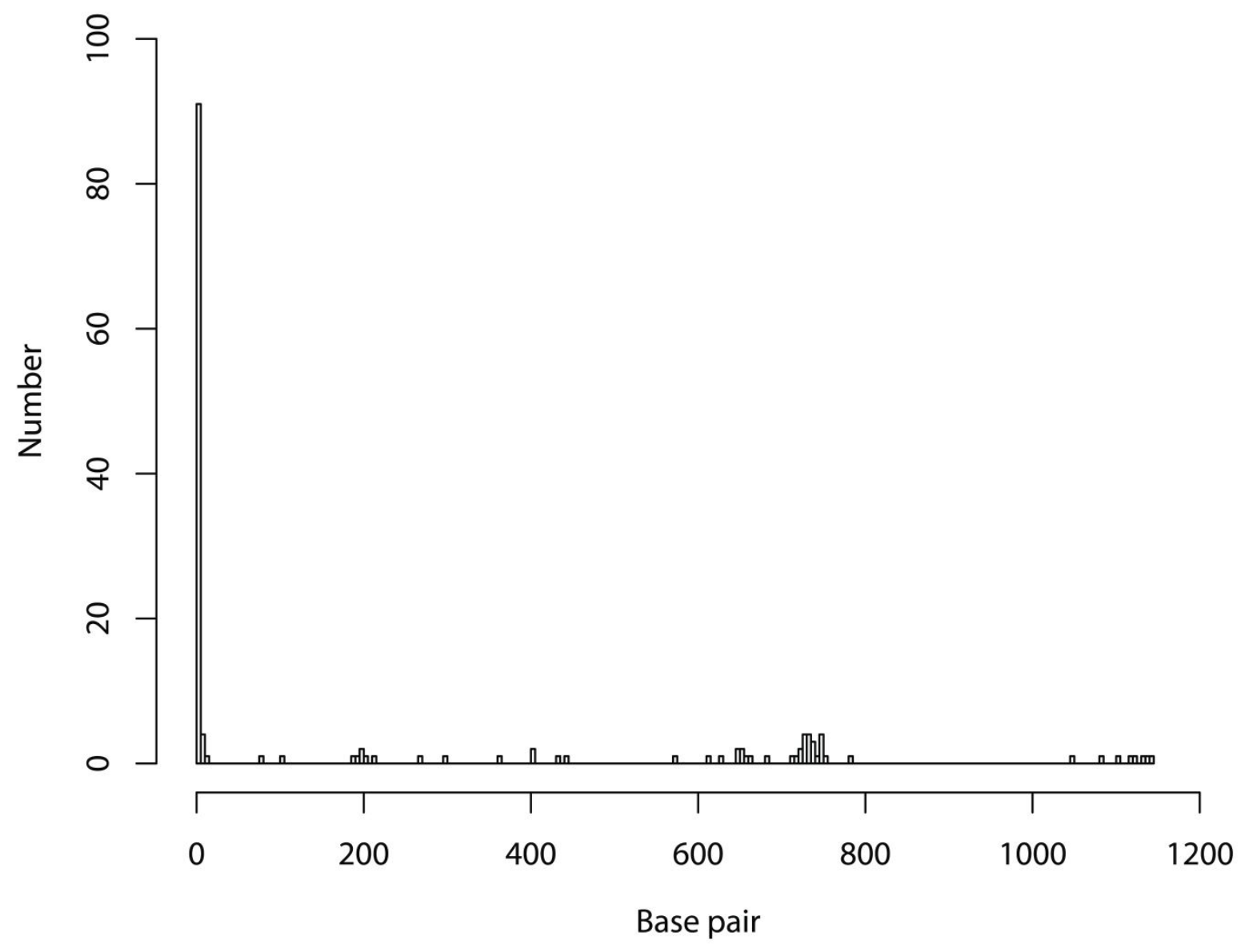




\section{Tables}

Table S1. Baseline characteristics of household contacts $\leq 19$ years old and exposed to an index case with drug-sensitive tuberculosis, stratified by isoniazid prevention therapy.

\begin{tabular}{|c|c|c|c|c|c|}
\hline \multirow{3}{*}{ Characteristic } & \multicolumn{2}{|c|}{ No isoniazid } & \multicolumn{2}{|c|}{ Isoniazid } & \multirow{3}{*}{ p-value* } \\
\hline & \multicolumn{2}{|c|}{ preventive } & \multicolumn{2}{|c|}{ preventive } & \\
\hline & \multicolumn{2}{|c|}{ therapy } & \multicolumn{2}{|c|}{ therapy } & \\
\hline & $\mathrm{N}$ & $\%$ & $\mathrm{~N}$ & $\%$ & \\
\hline Age in years $(\mathrm{N}=3,164)$ & & & & & $<0.01$ \\
\hline 0 to 5 & 484 & $32 \%$ & 659 & $40 \%$ & \\
\hline 6 to 10 & 324 & $21 \%$ & 417 & $26 \%$ & \\
\hline 11 to 15 & 349 & $23 \%$ & 354 & $22 \%$ & \\
\hline 16 to 19 & 377 & $25 \%$ & 200 & $12 \%$ & \\
\hline Gender $(\mathrm{N}=3,164)$ & & & & & 0.33 \\
\hline Female & 786 & $51 \%$ & 806 & $49 \%$ & \\
\hline Male & 748 & $49 \%$ & 824 & $51 \%$ & \\
\hline HIV seropositive $(\mathrm{N}=3,128)$ & & & & & 0.12 \\
\hline No & 1,508 & $100 \%$ & 1,616 & 100 & \\
\hline Yes & 4 & $0 \%$ & 0 & $0 \%$ & \\
\hline Diabetes Mellitus $(\mathrm{N}=3,157)$ & & & & & 0.98 \\
\hline No & 1,529 & $100 \%$ & 1,627 & 100 & \\
\hline Yes & 1 & $0 \%$ & 0 & $0 \%$ & \\
\hline BCG scars $(\mathrm{N}=3,164)$ & & & & & 0.52 \\
\hline 0 & 299 & $19 \%$ & 294 & $18 \%$ & \\
\hline 1 & 1,197 & $78 \%$ & 1,299 & $80 \%$ & \\
\hline$\geq 2$ & 38 & $2 \%$ & 37 & $2 \%$ & \\
\hline Smoking status $(\mathrm{N}=3,159)$ & & & & & $<0.01$ \\
\hline Non-smoker & 1,494 & $98 \%$ & 1,621 & 100 & \\
\hline 1 cigarette per day & 19 & $1 \%$ & 5 & $0 \%$ & \\
\hline$>1$ cigarette per day & 17 & $1 \%$ & 3 & $0 \%$ & \\
\hline Alcohol use $(\mathrm{N}=3,151)$ & & & & & $<0.01$ \\
\hline Non-drinker & 1,384 & $91 \%$ & 1,557 & $96 \%$ & \\
\hline 0 to $<3$ drinks per day & 111 & $7 \%$ & 60 & $4 \%$ & \\
\hline$\geq 3$ drinks per day & 31 & $2 \%$ & 8 & $0 \%$ & \\
\hline Nutritional status $^{\dagger}(\mathrm{N}=3,132)$ & & & & & 0.07 \\
\hline Normal weight & 1,269 & $84 \%$ & 1,299 & $81 \%$ & \\
\hline Underweight & 31 & $2 \%$ & 46 & $3 \%$ & \\
\hline Overweight & 219 & $14 \%$ & 268 & $17 \%$ & \\
\hline Use of public transportation $(\mathrm{N}=3,105)$ & & & & & 0.12 \\
\hline Non-user & 530 & $35 \%$ & 629 & $40 \%$ & \\
\hline
\end{tabular}




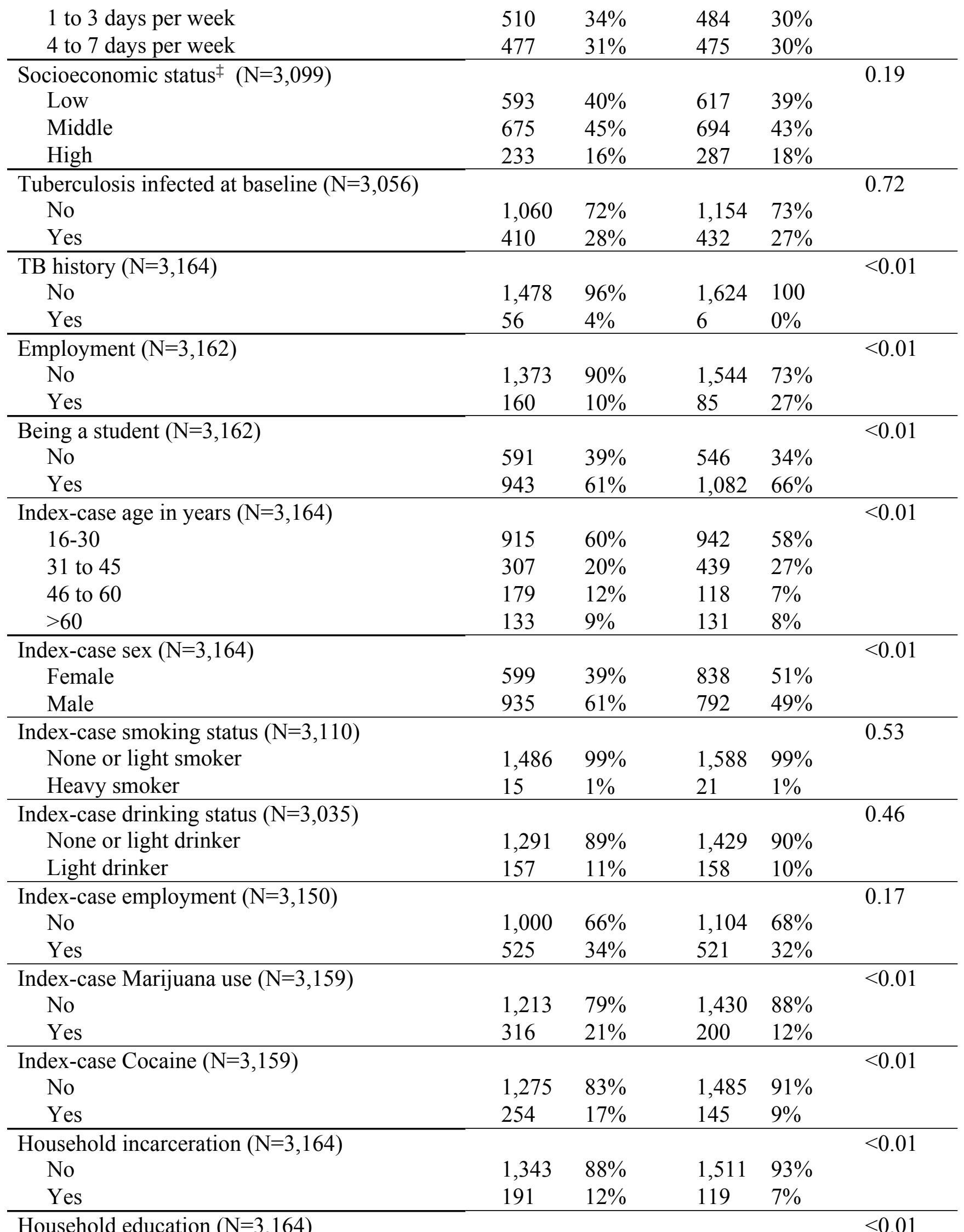




\begin{tabular}{|c|c|c|c|c|c|}
\hline Low & 361 & $24 \%$ & 302 & $19 \%$ & \\
\hline Medium & 887 & $58 \%$ & 927 & $57 \%$ & \\
\hline High & 286 & $19 \%$ & 401 & $25 \%$ & \\
\hline Household district $(\mathrm{N}=3,164)$ & & & & & $<0.01$ \\
\hline Cercado de Lima & 180 & $12 \%$ & 96 & $6 \%$ & \\
\hline Comas & 97 & $6 \%$ & 117 & $7 \%$ & \\
\hline El Agustino & 193 & $13 \%$ & 36 & $2 \%$ & \\
\hline La Victoria & 193 & $13 \%$ & 153 & $9 \%$ & \\
\hline Los Olivos & 144 & $9 \%$ & 188 & $12 \%$ & \\
\hline Rimac & 60 & $4 \%$ & 250 & $15 \%$ & \\
\hline San Martin de Porres & 261 & $17 \%$ & 452 & $28 \%$ & \\
\hline Santa Anita & 115 & $7 \%$ & 71 & $4 \%$ & \\
\hline Others & 291 & $19 \%$ & 267 & $16 \%$ & \\
\hline
\end{tabular}

${ }^{*}$ Compared the two groups used a $\chi^{2}$ test

${ }^{\dagger}$ Nutritional status was defined by the WHO body mass index z-score tables

¥ Socioeconomic status was defined using a principal component analysis based on housing quality, Abbreviation: N: number; MDR: multi-drug resistant 
Table S2. Baseline characteristics of household contacts $\leq 19$ years old and exposed to an index case with MDR tuberculosis, stratified by isoniazid prevention therapy.

\begin{tabular}{|c|c|c|c|c|c|}
\hline \multirow{4}{*}{ Characteristic } & \multirow{3}{*}{\multicolumn{2}{|c|}{$\begin{array}{l}\text { No isoniazid } \\
\text { preventive } \\
\text { therapy }\end{array}$}} & \multicolumn{2}{|c|}{ Isoniazid } & \multirow{4}{*}{ p-value } \\
\hline & & & \multirow{2}{*}{\multicolumn{2}{|c|}{$\begin{array}{c}\text { preventive } \\
\text { therapy }\end{array}$}} & \\
\hline & & & & & \\
\hline & $\mathrm{N}$ & $\%$ & $\mathrm{~N}$ & $\%$ & \\
\hline Age in years $(\mathrm{N}=666)$ & & & & & $<0.01$ \\
\hline 0 to 5 & 124 & $31 \%$ & 118 & $45 \%$ & \\
\hline 6 to 10 & 83 & $21 \%$ & 67 & $25 \%$ & \\
\hline 11 to 15 & 101 & $25 \%$ & 51 & $19 \%$ & \\
\hline 16 to 19 & 93 & $23 \%$ & 29 & $11 \%$ & \\
\hline Gender $(\mathrm{N}=666)$ & & & & & 0.07 \\
\hline Female & 215 & $54 \%$ & 122 & $46 \%$ & \\
\hline Male & 186 & $46 \%$ & 143 & $54 \%$ & \\
\hline HIV seropositive $(\mathrm{N}=658)$ & & & & & NA \\
\hline No & 398 & 100 & 260 & $100 \%$ & \\
\hline Yes & 0 & $0 \%$ & 0 & $0 \%$ & \\
\hline Diabetes Mellitus $(\mathrm{N}=663)$ & & & & & 1 \\
\hline No & 399 & 100 & 262 & $100 \%$ & \\
\hline Yes & 1 & $0 \%$ & 1 & $0 \%$ & \\
\hline BCG scars $(\mathrm{N}=666)$ & & & & & 0.54 \\
\hline 0 & 88 & $22 \%$ & 53 & $20 \%$ & \\
\hline 1 & 301 & $75 \%$ & 207 & $78 \%$ & \\
\hline$\geq 2$ & 12 & $3 \%$ & 5 & $2 \%$ & \\
\hline Smoking status $(\mathrm{N}=666)$ & & & & & 0.19 \\
\hline Non-smoker & 396 & $99 \%$ & 265 & $100 \%$ & \\
\hline 1 cigarette per day & 2 & $0 \%$ & 0 & $0 \%$ & \\
\hline$>1$ cigarette per day & 3 & $1 \%$ & 0 & $0 \%$ & \\
\hline Alcohol use $(\mathrm{N}=661)$ & & & & & $<0.01$ \\
\hline Non-drinker & 366 & $92 \%$ & 259 & $98 \%$ & \\
\hline 0 to $<3$ drinks per day & 24 & $6 \%$ & 4 & $2 \%$ & \\
\hline$\geq 3$ drinks per day & 7 & $2 \%$ & 1 & $0 \%$ & \\
\hline Nutritional status $^{\mathrm{b}}(\mathrm{N}=658)$ & & & & & 0.35 \\
\hline Normal weight & 331 & $83 \%$ & 214 & $83 \%$ & \\
\hline Underweight & 7 & $2 \%$ & 9 & $3 \%$ & \\
\hline Overweight & 61 & $15 \%$ & 36 & $14 \%$ & \\
\hline Use of public transportation $(\mathrm{N}=643)$ & & & & & 0.49 \\
\hline Non-user & 145 & $37 \%$ & 92 & $37 \%$ & \\
\hline 1 to 3 days per week & 129 & $33 \%$ & 89 & $36 \%$ & \\
\hline 4 to 7 days per week & 122 & $31 \%$ & 66 & $27 \%$ & \\
\hline Socioeconomic status $^{\mathrm{c}}(\mathrm{N}=664)$ & & & & & 0.09 \\
\hline Low & 149 & $37 \%$ & 119 & $45 \%$ & \\
\hline
\end{tabular}




\begin{tabular}{|c|c|c|c|c|c|}
\hline Middle & 183 & $46 \%$ & 100 & $38 \%$ & \\
\hline High & 68 & $17 \%$ & 45 & $17 \%$ & \\
\hline Tuberculosis infected at baseline $(\mathrm{N}=638)$ & & & & & $<0.01$ \\
\hline No & 236 & $62 \%$ & 205 & $80 \%$ & \\
\hline Yes & 146 & $38 \%$ & 51 & $20 \%$ & \\
\hline TB history $(\mathrm{N}=666)$ & & & & & $<0.01$ \\
\hline No & 386 & $96 \%$ & 265 & $100 \%$ & \\
\hline Yes & 15 & $4 \%$ & 0 & $0 \%$ & \\
\hline Employment $(\mathrm{N}=666)$ & & & & & 0.04 \\
\hline No & 357 & $89 \%$ & 249 & $94 \%$ & \\
\hline Yes & 44 & $11 \%$ & 16 & $6 \%$ & \\
\hline Being a student $(\mathrm{N}=666)$ & & & & & 0.76 \\
\hline No & 153 & $38 \%$ & 105 & $40 \%$ & \\
\hline Yes & 248 & $62 \%$ & 160 & $60 \%$ & \\
\hline Index-case age in years $(\mathrm{N}=666)$ & & & & & $<0.01$ \\
\hline $16-30$ & 247 & $60 \%$ & 942 & $58 \%$ & \\
\hline 31 to 45 & 82 & $20 \%$ & 439 & $27 \%$ & \\
\hline 46 to 60 & 50 & $12 \%$ & 118 & $7 \%$ & \\
\hline$>60$ & 22 & $9 \%$ & 131 & $8 \%$ & \\
\hline Index-case sex $(\mathrm{N}=666)$ & & & & & 0.99 \\
\hline Female & 174 & $43 \%$ & 114 & $43 \%$ & \\
\hline Male & 227 & $57 \%$ & 151 & $57 \%$ & \\
\hline Index-case smoking status $(\mathrm{N}=638)$ & & & & & 0.89 \\
\hline None or light smoker & 373 & $97 \%$ & 248 & $98 \%$ & \\
\hline Heavy smoker & 11 & $3 \%$ & 6 & $2 \%$ & \\
\hline Index-case employment $(\mathrm{N}=665)$ & & & & & 0.15 \\
\hline No & 285 & $71 \%$ & 174 & $66 \%$ & \\
\hline Yes & 115 & $29 \%$ & 91 & $34 \%$ & \\
\hline Index-case Marijuana use $(\mathrm{N}=662)$ & & & & & 0.58 \\
\hline No & 340 & $86 \%$ & 222 & $88 \%$ & \\
\hline Yes & 57 & $14 \%$ & 43 & $12 \%$ & \\
\hline Index-case Cocaine $(\mathrm{N}=661)$ & & & & & 0.52 \\
\hline No & 340 & $86 \%$ & 233 & $91 \%$ & \\
\hline Yes & 56 & $14 \%$ & 32 & $9 \%$ & \\
\hline Household incarceration $(\mathrm{N}=666)$ & & & & & 0.32 \\
\hline No & 347 & $87 \%$ & 237 & $93 \%$ & \\
\hline Yes & 57 & $13 \%$ & 28 & $7 \%$ & \\
\hline Household education $(\mathrm{N}=666)$ & & & & & 0.21 \\
\hline Low & 88 & $22 \%$ & 45 & $19 \%$ & \\
\hline Middle & 240 & $60 \%$ & 162 & $57 \%$ & \\
\hline High & 73 & $18 \%$ & 58 & $25 \%$ & \\
\hline Household district $(\mathrm{N}=666)$ & & & & & $<0.01$ \\
\hline Cercado de Lima & 30 & $7 \%$ & 21 & $8 \%$ & \\
\hline Comas & 3 & $1 \%$ & 10 & $4 \%$ & \\
\hline El Agustino & 83 & $21 \%$ & 16 & $6 \%$ & \\
\hline
\end{tabular}


La Victoria

Los Olivos

Rimac

San Martin de Porres

Santa Anita

Others

${ }^{a}$ Compared the two groups used a $\chi^{2}$ test

${ }^{\mathrm{b}}$ Nutritional status was defined by the WHO body mass index z-score tables

c Socioeconomic status was defined using a principal component analysis based on housing quality, Abbreviation: N: number; MDR: multi-drug resistant

\begin{tabular}{cccc}
62 & $15 \%$ & 19 & $7 \%$ \\
51 & $13 \%$ & 28 & $11 \%$ \\
7 & $2 \%$ & 30 & $11 \%$ \\
81 & $20 \%$ & 87 & $33 \%$ \\
18 & $4 \%$ & 10 & $4 \%$ \\
66 & $16 \%$ & 44 & $17 \%$ \\
\hline
\end{tabular}


Table S3. Baseline characteristics of household contacts $\leq 19$ years old and exposed to an index case with isoniazid-mono resistant tuberculosis, stratified by isoniazid prevention therapy.

\begin{tabular}{|c|c|c|c|c|c|}
\hline \multirow{3}{*}{ Characteristic } & \multicolumn{2}{|c|}{ No isoniazid } & \multicolumn{2}{|c|}{ Isoniazid } & \multirow{3}{*}{$\mathrm{p}$-value } \\
\hline & \multirow{2}{*}{\multicolumn{2}{|c|}{$\begin{array}{c}\text { preventive } \\
\text { therapy }\end{array}$}} & \multirow{2}{*}{\multicolumn{2}{|c|}{$\begin{array}{c}\text { preventive } \\
\text { therapy }\end{array}$}} & \\
\hline & & & & & \\
\hline & $\mathrm{N}$ & $\%$ & $\mathrm{~N}$ & $\%$ & \\
\hline Age in years $(\mathrm{N}=386)$ & & & & & $<0.01$ \\
\hline 0 to 5 & 56 & $30 \%$ & 78 & $39 \%$ & \\
\hline 6 to 10 & 32 & $17 \%$ & 48 & $24 \%$ & \\
\hline 11 to 15 & 39 & $21 \%$ & 46 & $23 \%$ & \\
\hline 16 to 19 & 58 & $31 \%$ & 29 & $14 \%$ & \\
\hline Gender $(\mathrm{N}=386)$ & & & & & 0.3 \\
\hline Female & 86 & $46 \%$ & 105 & $52 \%$ & \\
\hline Male & 99 & $54 \%$ & 96 & $48 \%$ & \\
\hline HIV seropositive $(\mathrm{N}=378)$ & & & & & NA \\
\hline No & 180 & $100 \%$ & 198 & $100 \%$ & \\
\hline Yes & 0 & $0 \%$ & 0 & $0 \%$ & \\
\hline Diabetes Mellitus $(\mathrm{N}=382)$ & & & & & 1 \\
\hline No & 183 & $100 \%$ & 198 & $99 \%$ & \\
\hline Yes & 0 & $0 \%$ & 1 & $1 \%$ & \\
\hline BCG scars $(\mathrm{N}=386)$ & & & & & 0.1 \\
\hline 0 & 36 & $19 \%$ & 54 & $27 \%$ & \\
\hline 1 & 142 & $77 \%$ & 144 & $72 \%$ & \\
\hline$\geq 2$ & 7 & $4 \%$ & 3 & $1 \%$ & \\
\hline Smoking status $(\mathrm{N}=384)$ & & & & & 0.04 \\
\hline Non-smoker & 178 & $97 \%$ & 200 & $100 \%$ & \\
\hline 1 cigarette per day & 4 & $2 \%$ & 0 & $0 \%$ & \\
\hline$>1$ cigarette per day & 2 & $1 \%$ & 0 & $0 \%$ & \\
\hline Alcohol use $(\mathrm{N}=383)$ & & & & & 0.11 \\
\hline Non-drinker & 162 & $89 \%$ & 190 & $95 \%$ & \\
\hline 0 to $<3$ drinks per day & 14 & $8 \%$ & 9 & $4 \%$ & \\
\hline$\geq 3$ drinks per day & 6 & $3 \%$ & 2 & $1 \%$ & \\
\hline Nutritional status ${ }^{\mathrm{b}}(\mathrm{N}=383)$ & & & & & 0.69 \\
\hline Normal weight & 148 & $81 \%$ & 168 & $84 \%$ & \\
\hline Underweight & 6 & $3 \%$ & 4 & $2 \%$ & \\
\hline Overweight & 28 & $15 \%$ & 29 & $14 \%$ & \\
\hline Use of public transportation $(\mathrm{N}=372)$ & & & & & 0.44 \\
\hline Non-user & 61 & $33 \%$ & 74 & $39 \%$ & \\
\hline 1 to 3 days per week & 70 & $38 \%$ & 67 & $36 \%$ & \\
\hline 4 to 7 days per week & 53 & $29 \%$ & 47 & $25 \%$ & \\
\hline
\end{tabular}

Socioeconomic status ${ }^{\mathrm{c}}(\mathrm{N}=365)$

0.12 


\begin{tabular}{|c|c|c|c|c|c|}
\hline $\begin{array}{l}\text { Low } \\
\text { Middle } \\
\text { High }\end{array}$ & $\begin{array}{l}79 \\
73 \\
24 \\
\end{array}$ & $\begin{array}{l}45 \% \\
41 \% \\
14 \%\end{array}$ & $\begin{array}{l}65 \\
93 \\
31\end{array}$ & $\begin{array}{l}34 \% \\
49 \% \\
16 \% \\
\end{array}$ & \\
\hline TB infected at baseline $(\mathrm{N}=374)$ & & & & & 0.94 \\
\hline No & 121 & $68 \%$ & 135 & $69 \%$ & \\
\hline Yes & 57 & $32 \%$ & 61 & $31 \%$ & \\
\hline TB history $(\mathrm{N}=386)$ & & & & & 0.45 \\
\hline No & 178 & $96 \%$ & 197 & $98 \%$ & \\
\hline Yes & 7 & $4 \%$ & 4 & $2 \%$ & \\
\hline Employment $(\mathrm{N}=386)$ & & & & & 0.09 \\
\hline No & 163 & $88 \%$ & 188 & $94 \%$ & \\
\hline Yes & 22 & $12 \%$ & 13 & $6 \%$ & \\
\hline Being a student $(\mathrm{N}=386)$ & & & & & 0.66 \\
\hline No & 65 & $35 \%$ & 76 & $38 \%$ & \\
\hline Yes & 120 & $65 \%$ & 126 & $62 \%$ & \\
\hline Index-case age in years $(\mathrm{N}=386)$ & & & & & 0.28 \\
\hline $16-30$ & 102 & $55 \%$ & 102 & $51 \%$ & \\
\hline 31 to 45 & 49 & $26 \%$ & 69 & $34 \%$ & \\
\hline 46 to 60 & 23 & $12 \%$ & 17 & $8 \%$ & \\
\hline$>60$ & 11 & $6 \%$ & 13 & $6 \%$ & \\
\hline Index-case sex $(\mathrm{N}=386)$ & & & & & 0.8 \\
\hline Female & 63 & $43 \%$ & 72 & $43 \%$ & \\
\hline Male & 122 & $57 \%$ & 129 & $57 \%$ & \\
\hline Index-case smoking status $(\mathrm{N}=377)$ & & & & & 0.22 \\
\hline None or light smoker & 178 & $98 \%$ & 185 & $95 \%$ & \\
\hline Heavy smoker & 4 & $2 \%$ & 10 & $5 \%$ & \\
\hline Index-case drinking status $(\mathrm{N}=378)$ & & & & & 0.44 \\
\hline None or light drinker & 155 & $86 \%$ & 175 & $89 \%$ & \\
\hline Heavy drinker & 26 & $14 \%$ & 22 & $11 \%$ & \\
\hline Index-case employment $(\mathrm{N}=385)$ & & & & & $<0.01$ \\
\hline $\mathrm{D}$ & 127 & $69 \%$ & 106 & $53 \%$ & \\
\hline Yes & 57 & $31 \%$ & 95 & $47 \%$ & \\
\hline Index-case Marijuana use (N=385) & & & & & 0.05 \\
\hline No & 162 & $88 \%$ & 159 & $90 \%$ & \\
\hline Yes & 23 & $12 \%$ & 41 & $10 \%$ & \\
\hline Index-case Cocaine $(\mathrm{N}=386)$ & & & & & 0.61 \\
\hline No & 159 & $86 \%$ & 168 & $90 \%$ & \\
\hline Yes & 26 & $14 \%$ & 33 & $10 \%$ & \\
\hline Household incarceration $(\mathrm{N}=386)$ & & & & & 0.86 \\
\hline No & 173 & $94 \%$ & 186 & $90 \%$ & \\
\hline Yes & 12 & $6 \%$ & 15 & $10 \%$ & \\
\hline Household education $(\mathrm{N}=386)$ & & & & & $<0.01$ \\
\hline Low & 50 & $27 \%$ & 27 & $68 \%$ & \\
\hline Middle & 75 & $41 \%$ & 116 & $32 \%$ & \\
\hline
\end{tabular}




\begin{tabular}{llllll} 
High & 60 & $32 \%$ & 58 & $68 \%$ & \\
\hline Household district (N=386) & & & & & $<0.01$ \\
$\quad$ Cercado de lima & 28 & $15 \%$ & 18 & $9 \%$ & \\
Comas & 12 & $6 \%$ & 8 & $4 \%$ & \\
El Agustino & 18 & $10 \%$ & 0 & $0 \%$ & \\
La Victoria & 18 & $10 \%$ & 6 & $3 \%$ & \\
Los Olivos & 17 & $9 \%$ & 22 & $11 \%$ & \\
Rimac & 17 & $9 \%$ & 43 & $21 \%$ & \\
San Martin de Porres & 31 & $17 \%$ & 66 & $33 \%$ & \\
Santa Anita & 5 & $3 \%$ & 2 & $1 \%$ & \\
Others & 39 & $21 \%$ & 36 & $18 \%$ & \\
\hline
\end{tabular}

${ }^{\mathrm{a}}$ Compared the two groups used a $\chi^{2}$ test

${ }^{\mathrm{b}}$ Nutritional status was defined by the WHO body mass index z-score tables

c Socioeconomic status was defined using a principal component analysis based on housing quality, Abbreviation: N: number; MDR: multi-drug resistant 
Table S4. Effect of isoniazid prevention therapy on disease incidence of household contacts $\leq 19$ years of age by isoniazid resistant profile pattern of tuberculosis index cases

\begin{tabular}{|c|c|c|c|}
\hline & Cases/Person-year* & $\begin{array}{l}\text { Univariate } \\
\text { analysis }\end{array}$ & Multivariate** \\
\hline & & HR $(95 \% \mathrm{CI})$ & $\operatorname{HR}(95 \% \mathrm{CI})$ \\
\hline \multicolumn{4}{|l|}{$\begin{array}{l}\text { Isoniazid prevention } \\
\text { therapy }\end{array}$} \\
\hline No & $108 / 4,250$ & Ref & Ref \\
\hline Yes & $38 / 2,583$ & $0.33(0.22-0.48)$ & $0.31(0.2-0.47)$ \\
\hline \multicolumn{4}{|l|}{$\begin{array}{l}\text { Isoniazid resistant } \\
\text { profile }\end{array}$} \\
\hline Sensitive & $108 / 3,849$ & Ref & Ref \\
\hline MDR & $27 / 806$ & $1.17(0.74-1.85)$ & $0.97(0.6-1.56)$ \\
\hline $\begin{array}{l}\text { Mono-isoniazid- } \\
\text { resistant }\end{array}$ & $11 / 470$ & $0.82(0.43-1.59)$ & $0.8(0.41-1.56)$ \\
\hline
\end{tabular}

** Numbers for univariate analyses

*Adjusted for index case age, recreational drug use, household contact age, gender, BCGvaccination scar, nutritional status, being a student or not, tuberculosis history, household socioeconomic status, and household residential district Abbreviations: HR: Hazard ratio; CI: confidence interval; Ref: Reference group; MDR: multidrug resistant. 
Table S5. The effect of isoniazid prevention therapy on tuberculosis incidence in $\leq 19$ year olds, by isoniazid resistance status of index patient, adjusted for index case age, household contact age, gender, BCG-vaccination scar, nutritional status, being a student or not, tuberculosis history, recreational use of index case, household socio-economic status, and household residential district.

\section{A. Complete dataset}

\begin{tabular}{|c|c|c|c|c|c|c|}
\hline \multirow{2}{*}{$\begin{array}{l}\text { Isoniazid } \\
\text { prevention } \\
\text { therapy }\end{array}$} & \multicolumn{2}{|c|}{ Isoniazid-sensitive } & \multicolumn{2}{|c|}{ MDR } & \multicolumn{2}{|c|}{ Mono-isoniazid resistant } \\
\hline & Cases/Person-year & $\operatorname{HR}(95 \% \mathrm{CI})$ & Cases/Person-year & $\operatorname{HR}(95 \% \mathrm{CI})$ & Cases/Person-year & $\operatorname{HR}(95 \% \mathrm{CI})$ \\
\hline No & $78 / 1,782$ & Ref & $23 / 474$ & Ref & $6 / 209$ & Ref \\
\hline Yes & $28 / 1,947$ & $0.3(0.18-0.48)$ & $3 / 320$ & $0.19(0.05-0.66)$ & $5 / 231$ & $0.8(0.23-2.8)$ \\
\hline
\end{tabular}

Likelihood ratio test for interaction term: $<0.001$

B. Household contacts who received isoniazid prevention therapy $\geq 3$ months

\begin{tabular}{|c|c|c|c|c|c|c|}
\hline \multirow{2}{*}{$\begin{array}{l}\text { Isoniazid } \\
\text { prevention } \\
\text { therapy }\end{array}$} & \multicolumn{2}{|c|}{ Isoniazid-sensitive } & \multicolumn{2}{|c|}{ MDR } & \multicolumn{2}{|c|}{ Mono-isoniazid resistant } \\
\hline & Cases/Person-year & $\operatorname{HR}(95 \% \mathrm{CI})$ & Cases/Person-year & $\operatorname{HR}(95 \% \mathrm{CI})$ & Cases/Person-year & $\operatorname{HR}(95 \% \mathrm{CI})$ \\
\hline No & $78 / 1,782$ & Ref & $23 / 474$ & Ref & $6 / 209$ & Ref \\
\hline Yes & $10 / 1133$ & $0.17(0.08-0.35)$ & $1 / 127$ & $0.17(0.02-1.34)$ & $3 / 150$ & $0.69(0.15-3.09)$ \\
\hline
\end{tabular}

Likelihood ratio test for interaction term: $<0.001$

C. Household contacts who received isoniazid prevention therapy $<3$ months

\begin{tabular}{|c|c|c|c|c|c|c|}
\hline \multirow{2}{*}{$\begin{array}{l}\text { Isoniazid } \\
\text { prevention } \\
\text { therapy }\end{array}$} & \multicolumn{2}{|c|}{ Isoniazid-sensitive } & \multicolumn{2}{|c|}{ MDR } & \multicolumn{2}{|c|}{ Mono-isoniazid resistant } \\
\hline & Cases/Person-year & HR $(95 \%$ CI $)$ & Cases/Person-year & HR $(95 \%$ CI $)$ & Cases/Person-year & HR $(95 \%$ CI $)$ \\
\hline No & $78 / 1,782$ & Ref & $23 / 474$ & Ref & $6 / 209$ & Ref \\
\hline Yes & $10 / 273$ & $0.89(0.43-1.83)$ & $1 / 77$ & $0.31(0.03-1.98)$ & $1 / 42$ & $1.31(0.14-11.95)$ \\
\hline
\end{tabular}

Likelihood ratio test for interaction term: 0.255 
Table S6. The effect of isoniazid prevention therapy on tuberculosis incidence in baseline infected $\leq 19$ year olds, by isoniazid resistance status of index patient, adjusted for index case age, household contact age, gender, BCG-vaccination scar, nutritional status, being a student or not, tuberculosis history, recreational use of index case, household socio-economic status, and household residential district.

\begin{tabular}{|c|c|c|c|c|c|c|}
\hline \multirow{2}{*}{$\begin{array}{l}\text { Isoniazid } \\
\text { prevention } \\
\text { therapy }\end{array}$} & \multicolumn{2}{|c|}{ Isoniazid-sensitive } & \multicolumn{2}{|c|}{ MDR } & \multicolumn{2}{|c|}{ Mono-isoniazid resistant } \\
\hline & Cases/Person-year & $\mathrm{HR}(95 \% \mathrm{CI})$ & Cases/Person-year & $\mathrm{HR}(95 \% \mathrm{CI})$ & Cases/Person-year & $\operatorname{HR}(95 \% \mathrm{CI})$ \\
\hline No & $58 / 434$ & Ref & $18 / 164$ & Ref & $3 / 66$ & Ref \\
\hline Yes & $16 / 504$ & $0.19(0.1-0.35)$ & $1 / 61$ & $0.14(0.02-1.07)$ & $4 / 69$ & $1.09(0.23-5.3)$ \\
\hline
\end{tabular}

Likelihood ratio test for interaction term: $<0.001$ 
Table S7. Isoniazid preventive therapy provided and outcomes achieved.

\begin{tabular}{|c|c|c|c|c|c|}
\hline Study & Region & Treatment & $\begin{array}{l}\text { Treatment } \\
\text { group } \\
\text { (case/total N) }\end{array}$ & $\begin{array}{l}\text { Control group } \\
\text { (case/total N) }\end{array}$ & Follow up time \\
\hline Kritski Brazil 1996 (13) & Brazil & High dose & $2 / 45$ & 145 & $\begin{array}{l}\text { 10,604-person- } \\
\text { months }\end{array}$ \\
\hline Schaaf et al. 2002 (14) & $\begin{array}{l}\text { South } \\
\text { Africa }\end{array}$ & $\begin{array}{l}\text { Various, all have } \\
\text { isoniazid }\end{array}$ & $2 / 41$ & $13 / 64$ & 30 months \\
\hline Attamna et al. 2009 (15) & Israel & Isoniazid & $0 / 71$ & $0 / 387$ & 2,666 person years \\
\hline Tochon et al. 2011(16) & France & $\begin{array}{l}\text { Isoniazid and } \\
\text { rifampin up to } 3 \\
\text { month }\end{array}$ & $1 / 6$ & NA & NA \\
\hline $\begin{array}{l}\text { Denholm et al. } 2012 \\
\text { (17) }\end{array}$ & Australia & $\begin{array}{l}\text { Various (all were not } \\
\text { under regular } \\
\text { isoniazid preventive } \\
\text { therapy) }\end{array}$ & $0 / 11$ & $2 / 38$ & Median 54 months \\
\hline Seddon et al. 2013 (18) & $\begin{array}{l}\text { South } \\
\text { Africa }\end{array}$ & $\begin{array}{l}\text { High dose isoniazid, } \\
\text { ethionamide and } \\
\text { ofloxacin }\end{array}$ & $6 / 187$ & NA & 219 patient-years \\
\hline $\begin{array}{l}\text { Garcia-Prat et al. } 2014 \\
\text { (19) }\end{array}$ & $\begin{array}{l}\text { South } \\
\text { Africa }\end{array}$ & $\begin{array}{l}\text { High dose isoniazid, } \\
\text { ethionamide and } \\
\text { ofloxacin }\end{array}$ & $0 / 21$ & $0 / 10$ & 1 year \\
\hline Wu et al. $2018(20)$ & China & Isoniazid & $2 / 5$ & $4 / 16$ & 6 months \\
\hline
\end{tabular}




\section{Reference}

1. Frothingham R, Meeker-O'Connell WA. Genetic diversity in the Mycobacterium tuberculosis complex based on variable numbers of tandem DNA repeats. Microbiology 1998; 144: 1189-96.

2. $\quad$ https://support.illumina.com/content/dam/illuminasupport/documents/documentation/system documentation/hiseq4000/hiseq-4000system-guide-15066496-04.pdf (accessed April 1, 2019)

3. Li H. Toward better understanding of artifacts in variant calling from high-coverage samples. Bioinformatics 2014; 30: 2843-51.

4. Li H, Handsaker B, Fenell T, et al. The Sequence Alignment/Map format and SAMtools. Bioinformatics 2009 25: 2078-9.

5. Walker BJ, Abeel T, Shea T, et.al. Pilon: an integrated tool for comprehensive microbial variant detection and genome assembly improvement. PLoS One 2014 19;9(11):e112963

6. Ministerio de Salud. Norma técnica de salud para el control de la tuberculosis. Lima, Peru, 2006. Available from: ftp://ftp2.minsa.gob.pe/descargas/dgsp/ESNtuberculosis/normaspublicaciones/NTStuberculosis,C.pdf (accessed October 10, 2018).

7. World Health Organization. Child growth standards. 2011 Available from: http://www.who.int/childgrowth/software/en/. Accessed 14 December 2015.

8. Graham SM, Ahmed T, Amanullah F, et al. Evaluation of tuberculosis diagnostics in children: Proposed clinical case definitions for classification of intrathoracic tuberculosis disease. Consensus from an expert panel. J Infect Dis 2012 205(Suppl 2): S199-208.

9. O'Quigley J, Stare J. Proportional hazards models with frailties and random effects. Stat Med 2002; 21(21): 3219-33.

10. International Union Against Tuberculosis Committee on Prophylaxis. Efficacy of various durations of isoniazid preventive therapy for tuberculosis: five years of follow-up in the UAT trial. Bull World Health Organ 1982; 60: 555-64.

11. Grandjean L, Gilman RH, Martin L et al. Transmission of Multidrug-Resistant and Drug-Susceptible Tuberculosis within Households: A Prospective Cohort Study. PLoS Med 2015; 12(6): e1001843

12. Caviedes L, Lee TS, Gilman RH, Sheen P, et al. Rapid, efficient detection and drug susceptibility testing of Mycobacterium tuberculosis in sputum by microscopic observation of broth cultures. The Tuberculosis Working Group in Peru. J Clin Microbiol 2000; 38: 12-1208.

13. Kritski AL, Marques MJ, Rabahi MF, et al. Transmission of tuberculosis to close contacts of patients with multidrug-resistant tuberculosis. Am J Respir Crit Care Med 1996; 153(1): 331-5.

14. Schaaf HS, Gie RP, Kennedy M, Beyers N, Hesseling PB, Donald PR. Evaluation of young children in contact with adult multidrug-resistant pulmonary tuberculosis: a 30-month follow-up. Pediatrics 2002; 109: 765-71. 
15. Attamna A, Chemtob D, Attamna S, et al. Risk of tuberculosis in close contacts of patients with multidrug resistant tuberculosis: a nationwide cohort. Thorax 2009; 64: 271.

16. Tochon M, Bosdure E, Salles M, et al. Management of young children in contact with an adult with drug-resistant tuberculosis, France, 2004-2008. Int J Tuberc Lung Dis 2011; 15: 326-30.

17. Denholm JT, Leslie DE, Jenkin GA, et al. Long-term follow-up of contacts exposed to multidrug-resistant tuberculosis in Victoria, Australia, 1995 -2010. Int J Tuberc Lung Dis 2012; 16: 1320-5.

18. Seddon JA, Hesseling AC, Finlayson H, et al. Preventive therapy for child contacts of multidrug-resistant tuberculosis: a prospective cohort study. Clin Infect Dis 2013; 57: 1676-84.

19. Garcia-Prats AJ, Zimri K, Mramba Z, Schaaf HS, Hesseling AC. Children exposed to multidrug-resistant tuberculosis at a home-based day care centre: a contact investigation. Int J Tuberc Lung Dis 2014; 18: 1292-8.

20. Wu X, Pang Y, Song Y, et al. Implications of a school outbreak of multidrug-resistant tuberculosis in Northern China. Epidemiol Infect 2018; 145(5):584-8. 